\title{
Tropical Intraseasonal Variability in Version 3 of the GFDL Atmosphere Model
}

\author{
JAMES J. BENEDICT AND ERIC D. MALONEY \\ Department of Atmospheric Science, Colorado State University, Fort Collins, Colorado \\ ADAM H. SOBEL \\ Department of Applied Mathematics, Department of Earth and Environmental Sciences, and Lamont-Doherty \\ Earth Observatory, Columbia University, New York, New York \\ DARGAN M. FRIERSON \\ Department of Atmospheric Sciences, University of Washington, Seattle, Washington \\ LEO J. DONNER \\ NOAA/Geophysical Fluid Dynamics Laboratory, Princeton, New Jersey
}

(Manuscript received 24 February 2012, in final form 3 July 2012)

\begin{abstract}
Tropical intraseasonal variability is examined in version 3 of the Geophysical Fluid Dynamics Laboratory Atmosphere Model (AM3). In contrast to its predecessor AM2, AM3 uses a new treatment of deep and shallow cumulus convection and mesoscale clouds. The AM3 cumulus parameterization is a massflux-based scheme but also, unlike that in AM2, incorporates subgrid-scale vertical velocities; these play a key role in cumulus microphysical processes. The AM3 convection scheme allows multiphase water substance produced in deep cumuli to be transported directly into mesoscale clouds, which strongly influence large-scale moisture and radiation fields. The authors examine four AM3 simulations using a control model and three versions with different modifications to the deep convection scheme. In the control AM3, using a convective closure based on CAPE relaxation, both MJO and Kelvin waves are weak relative to those in observations. By modifying the convective closure and trigger assumptions to inhibit deep cumuli, AM3 produces reasonable intraseasonal variability but a degraded mean state. MJO-like disturbances in the modified AM3 propagate eastward at roughly the observed speed in the Indian Ocean but up to 2 times the observed speed in the west Pacific Ocean. Distinct differences in intraseasonal convective organization and propagation exist among the modified AM3 versions. Differences in vertical diabatic heating profiles associated with the MJO are also found. The two AM3 versions with the strongest intraseasonal signals have a more prominent "bottom heavy" heating profile leading the disturbance center and "top heavy" heating profile following the disturbance. The more realistic heating structures are associated with an improved depiction of moisture convergence and intraseasonal convective organization in AM3.
\end{abstract}

\section{Introduction}

In the tropical atmosphere, variability on 20-100-day time scales (hereafter, "intraseasonal") is dominated by the Madden-Julian oscillation (MJO) (Madden and Julian 1971). Kelvin and equatorial Rossby waves modify tropical

Corresponding author address: Jim Benedict, Department of Atmospheric Science, Colorado State University, Fort Collins, CO 80523-1371.

E-mail: jim@atmos.colostate.edu precipitation and wind distributions on shorter time scales. In the Indo-Pacific region, these disturbances typically involve a coupling between moist convection and the large-scale flow field. General circulation models (GCMs) use parameterizations to represent the bulk effects of these convective clouds on grid-scale heat, moisture, and momentum budgets. GCM simulations are often strongly sensitive to the choice of convective parameterization and parameter variations within a given parameterization scheme (e.g., Maloney and Hartmann 2001). The challenges of accurately simulating subgrid-scale clouds and the 
sensitivity to the convective parameterizations used have contributed to a poor depiction of intraseasonal convective systems in many GCMs (Slingo et al. 1996; Lin et al. 2006; Kim et al. 2009).

In this study, we examine intraseasonal convective disturbances in version 3 of the Geophysical Fluid Dynamics Laboratory (GFDL) Atmosphere Model (AM3) (Donner et al. 2011). For selected diagnostics, we also compare the AM3 results with those of its predecessor, AM2 (Anderson et al. 2004). Two important differences distinguish AM3 from AM2: 1) the AM3 deep convective parameterization utilizes plume momentum budgets to compute cumulus cell-scale updraft speeds and 2) AM3 uses a separate parameterization to assess the impact of dynamically active mesoscale anvil clouds on the large-scale heat and moisture budgets following Donner (1993). Vertical air motion within cumulus cells is closely linked to microphysical processes that in turn play a primary role in determining the rate of condensate formation in the cumulus cells. This condensate in cumuli is the dominant source of water substance for neighboring anvil clouds, which are a common feature of tropical convective systems and can significantly affect the local radiation budget (Houze 1982). Observational studies suggest that a substantial portion $(20 \%-60 \%)$ of total tropical precipitation is associated with stratiform mesoscale cloud systems (Houze 1989; Schumacher and Houze 2003; Yuan and Houze 2010). Whereas conventional convective parameterizations treat only direct interactions between cumuli and their grid-scale environment, the AM3 scheme accounts for mesoscale circulations that modulate the exchange of water substance as well as the radiative, dynamic, and thermodynamic properties within the cloud-environment system.

Aside from the changes to the deep convective parameterization mentioned above, the AM3 also implements advanced treatments of shallow convection, cloud-aerosol interactions, and stratosphere-troposphere coupling relative to AM2. Full details of the standard AM3 simulations are provided in Donner et al. (2011), but here we highlight results relevant to this study. The AM3 parameterizations are tuned to produce an optimal mean state, but some climatological biases remain including excessive deep convection in the Indian Ocean and west Pacific regions. Tropical interannual variability is broadly consistent with observations (see Fig. 18 in Donner et al. 2011), but subseasonal features such as Kelvin waves, the MJO, and tropical cyclones are poorly simulated. Donner et al. indicate that modifications made to the convective closure and trigger assumptions improve aspects of intraseasonal convection but also increase mean state biases, a common trade-off found in most GCMs (e.g., Kim et al. 2011). We will examine additional details of this and other modified AM3 simulations in section 3 .

A key linkage between parameterized convection and the depiction in GCMs of intraseasonal convective disturbances involves spatial structures of moistening and diabatic heating. In nature, convectively active regions often exhibit a top-heavy heating structure with a peak occurring between 400 and $500 \mathrm{hPa}$ (e.g., Yanai et al. 1973). In a time mean sense, this profile is known to result from the combined effects of deep convective, stratiform, and shallow convective heating (Houze 1982; Lin and Johnson 1996; Lau and Wu 2010). However, cloud systems evolve on hourly to intraseasonal time scales with characteristic heating profiles during each phase of their life cycle. Lin et al. (2004) noted that the structure of maximum diabatic heating tilts westward with height for MJO disturbances and that this tilt was associated with a progression of shallow to deep to stratiform cloud types. This westward tilt with height is a common feature of many organized tropical convective systems as discussed in numerous observational and theoretical studies (e.g., Moncrieff 1992, 2004; Kiladis et al. 2005). Lau and Wu (2010) used the Tropical Rainfall Measuring Mission (TRMM; Kummerow et al. 2000) precipitation radar to highlight the cumulus deepening and the transition to stratiform clouds during different MJO stages. A similar evolution in cloud populations and their associated heating structures is seen in many other convectively coupled equatorial waves (Kiladis et al. 2009). These heating structures can drive multiscale circulations that broadly impact moisture availability and atmospheric stability, and thus the probability and characteristics of future convection. Numerous theories related to such feedbacks between convective heating and large-scale circulations have been proposed (e.g., Hayashi 1970; Emanuel 1987; Neelin et al. 1987; Wang 1988; Emanuel 1993), but an accurate, comprehensive model has yet to be established.

Several modeling studies have investigated the relationships between heating structures and intraseasonal convection. It is clear that simulated intraseasonal convective systems are sensitive to the vertical structure of diabatic heating, but exactly what type of heating structure is most favorable for generating and sustaining such disturbances in GCMs remains under debate. Some studies show that simulated MJO intensity and propagation can be improved if the contributions to the total heating profile by grid-scale stratiform heating become larger (Fu and Wang 2009; Seo and Wang 2010). Others have emphasized bottom-heavy shallow convective heating rather than top-heavy stratiform heating as being a primary contributor to tropical intraseasonal disturbances (Wu 2003; Zhang and Mu 2005; Li et al. 2009; 
Jia et al. 2010). The balance of evidence suggests that each heating structure-shallow, deep, and stratiformcontributes in some way to the observed space-time patterns of intraseasonal convective disturbances. Recent work has underscored the importance of threedimensional heating in MJO simulations. In one GCM study, the vertical heating profile is artificially adjusted to determine the optimal profile required for a realistic MJO simulation (Lappen and Schumacher 2012). The authors conclude that an accurate representation of the horizontal variation in the shape of the vertical heating profile-rather than a single representative vertical heating structure-is critical to generate a realistic MJO. The prominent role that spatially varying vertical heating profiles play in the simulation of intraseasonal convective systems is also noted in reduced-complexity models (Khouider and Majda 2007; Kuang 2008; Khouider et al. 2011).

The purpose of this study is to investigate changes to the depiction of intraseasonal convective systems that result from adjustments made to the deep convective parameterization scheme of the GFDL AM3. Our study complements the preliminary results of the AM3 simulation reported in Donner et al. (2011), but also examines in much greater detail the ability of modified versions of the model to produce realistic intraseasonal disturbances. Questions that we seek to address include the following: 1) What are the space-time and spectral characteristics of intraseasonal variability in the control AM3 and how does this compare to previous results from AM2 simulations? 2) Can we tune the AM3 to produce more realistic intraseasonal variability by making convection more inhibited, as is typical of many other GCMs (e.g., Tokioka et al. 1988)? If so, does the tuning degrade the mean state as in many other GCMs (e.g., Kim et al. 2011)? 3) Do moisture convergence and vertical heating profiles associated with the simulated intraseasonal disturbances vary systematically across our ensemble of modified AM3 simulations?

A description of the AM3, modifications made to its deep convection scheme, and the validation datasets used in this study are provided in section 2 . We review the simulation results in section 3 . In section 4 , we discuss the mechanisms associated with changes to the intraseasonal convective systems in the modified AM3 simulations. Concluding remarks are given in section 5 .

\section{Data and model description}

We analyze daily averaged output from two simulations of the AM2 and four simulations of the AM3 to investigate how modifying parameters of the deep convection scheme influences the tropical mean state and subseasonal variability. Each model is run for 11 years with the first year of output discarded to account for model spinup. All simulations are forced by observed longterm seasonal cycle monthly means in sea surface temperatures (SSTs) and sea ice concentrations. ${ }^{1}$

The AM2 simulations examined in this study are identical to those used by Sobel et al. (2010). AM2 utilizes a hydrostatic, finite-difference dynamical core run on a staggered Arakawa B horizontal grid with $2^{\circ}$ latitude and $2.5^{\circ}$ longitude resolution. A 24-level hybrid sigmapressure coordinate system is used in the vertical, with nine levels in the lowest $1.5 \mathrm{~km}$ of the atmosphere and a 3-hPa top. All moist convection is parameterized using a modified version of the relaxed Arakawa-Schubert scheme (RAS) of Moorthi and Suarez (1992). In this scheme, a spectrum of convective plumes exists, and each member has a characteristic lateral entrainment rate. Closure of the system of equations is based on a relaxation of the cloud work function [or convective available potential energy (CAPE) for a nonentraining parcel] back to a reference value over a specified time scale [Arakawa and Schubert (1974); see Eq. (2) in Wilcox and Donner (2007)]. The version of RAS used in the AM2 simulations shown in this study does not parameterize convective downdrafts. We note that this exclusion might hinder AM2's ability to correctly simulate MJO disturbances, as evidenced in Maloney and Hartmann (2001), who found that intraseasonal variability increases (becomes more realistic) when convective downdrafts are activated in the RAS scheme. Convective momentum transport (CMT) is represented by including an additional term $K_{\mathrm{cu}} \propto \gamma M_{\mathrm{C}}$ in the vertical momentum diffusion coefficient, where $M_{\mathrm{C}}$ is the total cumulus mass flux and $\gamma$ is a dimensionless constant whose value is chosen to minimize errors in mean and interannual tropical precipitation patterns while still being within a range suggested by cloud-resolving modeling studies [see Eq. (1) in Anderson et al. (2004)]. The downgradient diffusive treatment of CMT ensures numerical stability but strongly reduces tropical transient eddy activity relative to more conventional mass-flux-based formulations. This degradation is partially alleviated by suppressing deep convective formation for updrafts with lateral entrainment rates below a minimum threshold $\mu_{\min }=\alpha / D$, where $\alpha$ is a positive constant and $D$ is the planetary boundary

\footnotetext{
${ }^{1}$ AM2 is forced by the 1981-99 mean annual cycle derived from version 2 of the NOAA optimum interpolation SST and sea ice dataset (OI.v2) (Reynolds et al. 2002), while AM3 uses the 19812000 mean annual cycle from a data product that combines OI.v2 with version 1 of the Hadley Centre SST and sea ice dataset (Hurrell et al. 2008). For the purposes of our simulations, the two datasets are nearly identical.
} 
layer depth (Tokioka et al. 1988). In practice, $\alpha$ can be increased or reduced to make suppression of deep convection stronger or weaker, respectively (e.g., Hannah and Maloney 2011). Stronger suppression of convection in this manner tends to increase the overall rate of subseasonal transient eddies in the tropics (e.g., Tokioka et al. 1988; Kim et al. 2011). Additional details of the AM2 setup are provided in Anderson et al. (2004).

Many features of AM3 differ markedly from those of AM2. AM3 has a finite volume dynamical core on a cubed-sphere horizontal grid. The use of a cubed-sphere configuration, characterized by horizontal grid cell sizes ranging from 163 to $231 \mathrm{~km}$, greatly increases computational efficiency. Although the standard version of AM3 used in Donner et al. (2011) uses 48 levels and an advanced treatment of chemistry, the version used here has 32 levels and implements a simplified chemistry scheme as described in Salzmann et al. (2010) to increase computational efficiency. This "simplified" AM3 has more stratospheric levels than the AM2, but fewer than the standard AM3 (Donner et al. 2011).

Compared to AM2, AM3 implements new parameterizations for shallow and deep convection. Shallow convection is represented by a modified version of the Bretherton et al. (2004) scheme (see Zhao et al. 2009). Interactions among vertically dominant deep convective cells, ${ }^{2}$ their associated horizontally dominant mesoscale anvil clouds, and the environment are parameterized as described in Donner (1993), Donner et al. (2001), and Wilcox and Donner (2007). Because anvil clouds can have a substantial impact on precipitation and the radiation budget in the tropics (Houze 1982, 1989), some representation of mesoscale cloud effects, even if simplified, is desirable. The Donner formulation incorporates both cumulus cell-scale vertical momentum dynamics as well as traditionally implemented mass fluxes to diagnose the multiphase water budget of the cloud-environment system. Cumulus microphysical processes are strongly dependent on vertical velocity $w$ within convective cells, and the condensate produced within these cells is the dominant source of water substance to neighboring anvil clouds. Cumulus-scale $w$ is computed using a steady-state equation in which vertical advection of vertical momentum is changed by entrainment, condensate loading, and buoyancy [see Eq. (6) in Donner 1993]. Figure 1 depicts graphically the vapor and condensate pathways handled by the Donner deep convection scheme, although we

\footnotetext{
${ }^{2}$ A requirement for activation of the deep convection parameterization is that a rising air parcel must exhibit a pressure difference of at least $500 \mathrm{hPa}$ between its level of free convection and level of neutral buoyancy.
}

note that two simplified versions of the AM3 discussed below do not treat all pathways. Within each member of a spectrum of cumulus plumes with characteristic entrainment rates, condensate can be formed within convective updrafts $\left(C_{U}\right)$, evaporated directly into the environment near the cloud top $\left(E_{\mathrm{CE}}\right)$, evaporated within convective downdrafts $\left(E_{\mathrm{CD}}\right)$, removed from the cloud as precipitation $\left(R_{\mathrm{C}}\right)$, or transferred to an adjacent anvil cloud as liquid $\left(C_{A}\right)$ or vapor $\left(Q_{\mathrm{mf}}^{\prime}\right)$. Water substance supplied by cumulus cells to the dynamically active anvil cloud can undergo additional phase changes: condensate can be formed within mesoscale updrafts $\left(C_{\mathrm{MU}}\right)$, removed as precipitation $\left(R_{M}\right)$, or evaporated into the GCM gridscale environment from mesoscale updrafts $\left(E_{\mathrm{ME}}\right)$ or downdrafts $\left(E_{\mathrm{MD}}\right)$. We note that $E_{\mathrm{CD}}=0$ for two simplified versions of the AM3 (AM3-CTL and AM3-A).

Numerous simplifying assumptions within the Donner scheme are a direct result of the limited number of observations describing the physical processes within the cloud systems. For example, the moisture budget partitioning outlined above uses a semiempirical approach based on a very limited number of tropical convective system case studies from Leary and Houze (1980). Vertical profiles of evaporation and sublimation within cumulus updrafts and downdrafts also remain highly uncertain. Further details of the AM3 model setup can be found in Donner et al. (2011) and references therein.

We summarize key differences among the deep convection parameterizations in Table 1. The two AM2 simulations are identical except that the minimum entrainment parameter $\mu_{\min }$ is 4 times as large in the AM2-TOK simulation than in the AM2 control run (AM2-CTL). A larger $\mu_{\min }$ essentially represents stronger suppression of the deepest convective plumes, which has been shown to improve the depiction of intraseasonal convective disturbances in some GCMs (Tokioka et al. 1988; Hannah and Maloney 2011). In the AM2, nonprecipitated condensate is transferred to gridscale stratiform clouds. Evaporation of some (or all) of the condensate is then possible depending on the environment and history of the stratiform clouds, which are prognostically parameterized. Additionally, a CAPE relaxation closure assumption is used as described previously [Eq. (2) in Wilcox and Donner 2007].

Although the control AM3 simulation, AM3-CTL, uses the same type of closure assumption as in the AM2 runs, the convective parameterization is based upon the scheme of Donner (1993). In AM3-CTL, activation of deep cumulus formation is precluded if convective inhibition (CIN) is above $100 \mathrm{~J} \mathrm{~kg}^{-1}$. Additionally, a single CAPE threshold (1000 $\mathrm{J} \mathrm{kg}^{-1}$ ) and relaxation time scale are applied to the entire cumulus ensemble, whereas in AM2 the thresholds are assigned by each subensemble 


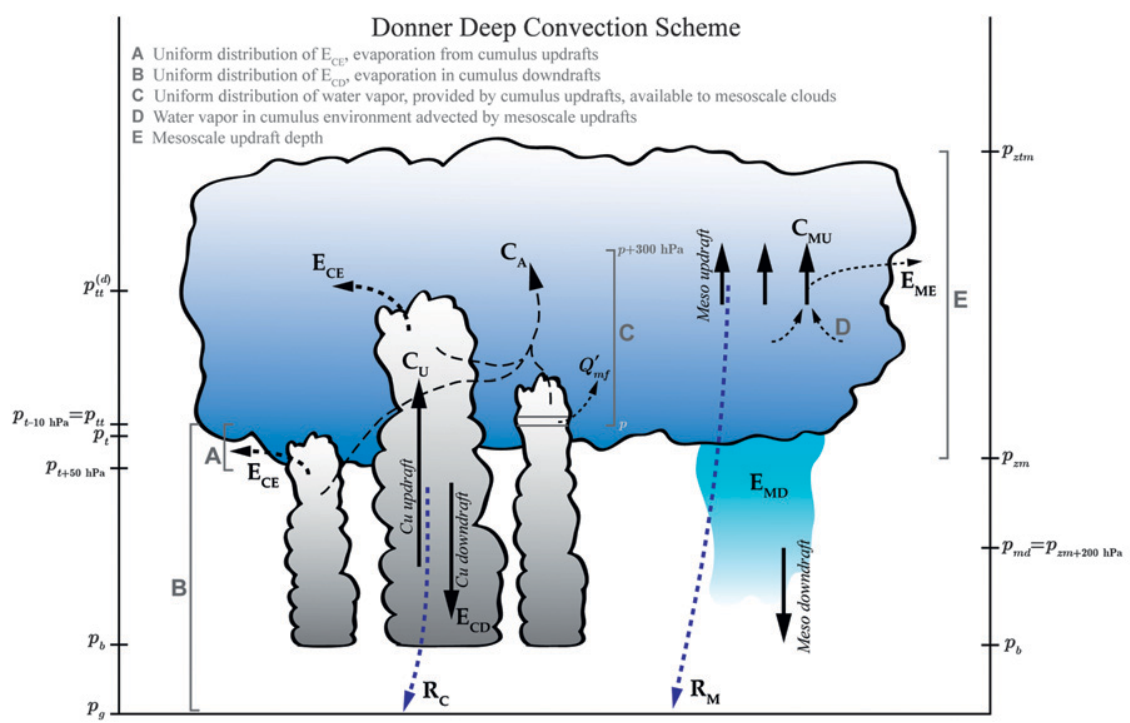

FIG. 1. Diagram of selected physical processes represented in the Donner deep convection scheme. Clouds associated with the cumulus (mesoscale) parameterizations are shaded gray (dark blue). For any member of a spectrum of cumuli, condensate can be formed within convective updrafts $\left(C_{U}\right)$, evaporated directly into the environment $\left(E_{\mathrm{CE}}\right)$ within the cloud-top zone, evaporated within convective downdrafts $\left(E_{\mathrm{CD}}\right)$, removed from the cloud as precipitation $\left(R_{C}\right)$, or transported to a mesoscale anvil cloud as liquid $\left(C_{A}\right)$ or vapor $\left(Q_{\mathrm{mf}}^{\prime}\right)$. Water substance provided by cumuli to the subgrid-scale anvil can undergo phase changes: condensate can be formed within mesoscale updrafts $\left(C_{\mathrm{MU}}\right)$, removed as precipitation $\left(R_{M}\right)$, or evaporated into the grid-scale environment from mesoscale updrafts $\left(E_{\mathrm{ME}}\right)$ or downdrafts $\left(E_{\mathrm{MD}}\right)$. The cloudtop zone, defined for each cumulus subensemble, is the region from $50 \mathrm{hPa}$ below cloud top $\left(p_{t}\right)$ to $10 \mathrm{hPa}$ above $p_{t}\left(p_{\mathrm{tt}}\right)$. The cloud-top pressure of the most penetrative cumulus plume is $p_{\mathrm{tt}}^{(d)}$. The mesoscale cloud updraft base pressure $p_{\mathrm{zm}}$ occurs where $Q_{\mathrm{mf}}^{\prime}$ first becomes positive for the least penetrative cumulus plume; its top extends to $p_{\mathrm{ztm}}$, where $p_{\mathrm{ztm}}$ is set at the level of zero buoyancy (LZB) or $p_{\mathrm{LZB}}-10 \mathrm{hPa}$, if $p_{t}$ for the deepest cell is less than $p_{\mathrm{LZB}}$. Also, $p_{\mathrm{ztm}}$ is restricted to be no less than the pressure at the temperature minimum taken as an indicator of the local tropopause. Sublimation associated with mesoscale downdrafts occurs in the layer from $p_{\mathrm{zm}}$ to the surface $\left(p_{g}\right)$, and light blue shading fading to white represents the reduction in relative humidity as mixing with environmental air occurs. Mesoscale downdrafts can exist between $p_{\mathrm{zm}}$ and $p_{g}$, and their associated fluxes of moisture and temperature are distributed as functions of height between $p_{\mathrm{md}}$ and cumulus cloud-base pressure $p_{b}$ and uniformly between $p_{\mathrm{zm}}$ and $p_{\mathrm{md}}$ and between $p_{b}$ and $p_{g}$.

member. The AM3-CTL is tuned such that $10 \%$ of nonprecipitated condensate formed in convective updrafts is exposed to the environment and possibly evaporated while the remaining $90 \%$ is transported into mesoscale clouds. AM3-A uses condensate partitioning identical to AM3-CTL but with modified convective closure and trigger assumptions. The modified closure assumption (Zhang 2002) is based on the idea that CAPE fluctuations associated with free-tropospheric temperature fluctuations driven by large-scale processes are balanced by changes in CAPE due to cumulus activity [see Eq. (3) in Wilcox and Donner (2007)]. In addition to the CAPE and CIN thresholds used to restrict deep convection activation in AM3-CTL, each AM3 experimental simulation employs a triggering mechanism requiring that time-integrated low-level ascent must exceed a selected value in order for deep cumuli to form [see Eqs. (6) and (7) in Donner et al. (2001)]. AM3-B is identical to AM3-A but incorporates a new partitioning of cumulus condensate for which $25 \%$ of nonprecipitated condensate is evaporated within convective downdrafts, $13 \%$ is evaporated directly into the environment, and $62 \%$ is entrained into mesoscale updrafts. The numerical values of the partitioning are based on observations of tropical convective systems as reported in Leary and Houze (1980). As a final modification in the experimental suite, AM3-C implements a more realistic CAPE calculation. For simplicity, CAPE is typically computed under the assumption that no mixing occurs between a rising parcel and its environment ("undilute" CAPE). This zero-entrainment assumption results in an unrealistically weak sensitivity of CAPE to free-tropospheric 
TABLE 1. Key features of the deep convective parameterizations used in the AM2 and AM3 simulations examined in this study. See text for further details.

\begin{tabular}{|c|c|c|c|c|c|c|c|}
\hline & \multicolumn{4}{|c|}{ Deep convection parameterization } & \multicolumn{3}{|c|}{ Nonprecipitated condensate pathways } \\
\hline & Scheme & $\begin{array}{c}\text { Closure } \\
\text { assumption }\end{array}$ & Activation trigger & $\begin{array}{l}\text { CAPE } \\
\text { dilution? }\end{array}$ & $\begin{array}{l}\text { Evaporation in } \\
\text { downdrafts }\end{array}$ & $\begin{array}{c}\text { Evaporation into } \\
\text { environment }\end{array}$ & $\begin{array}{l}\text { Entrained into } \\
\text { anvil clouds }\end{array}$ \\
\hline AM2-CTL & RAS & CAPE relaxation & $\alpha=0.025$ & No & 0 & 1 & - \\
\hline AM2-TOK & RAS & CAPE relaxation & $\alpha=0.1$ & No & 0 & 1 & - \\
\hline AM3-CTL & Donner & CAPE relaxation & - & No & 0 & 0.1 & 0.9 \\
\hline AM3-A & Donner & Zhang (2002) & $\begin{array}{l}\text { Time-integrated low-level } \\
\text { parcel lifting }\end{array}$ & No & 0 & 0.1 & 0.9 \\
\hline AM3-B & Donner & Zhang (2002) & $\begin{array}{l}\text { Time-integrated low-level } \\
\text { parcel lifting }\end{array}$ & No & 0.25 & 0.13 & 0.62 \\
\hline AM3-C & Donner & Zhang (2002) & $\begin{array}{l}\text { Time-integrated low-level } \\
\text { parcel lifting }\end{array}$ & Yes & 0.25 & 0.13 & 0.62 \\
\hline
\end{tabular}

humidity and temperature (Donner and Phillips 2003; Holloway and Neelin 2009). Versions 3 and 4 of the National Center for Atmospheric Research Community Climate System Model (CCSM) have shown a more realistic depiction of intraseasonal variability with the dilute CAPE approach (Neale et al. 2008; Subramanian et al. 2011; Zhou et al. 2012). In AM3-C, all CAPE calculations involve parcel-environment mixing whose strength is dependent on an assumed fractional entrainment rate $\mu=2 \times 10^{-4} \mathrm{~m}^{-1}$ that is constant with height. This choice of $\mu$ is representative of weakly entraining deep convection (Romps 2010). To experiment with changes in evaporation from convective cells and CAPE relaxation, AM3-B and AM3-C use a cloud model with higher vertical resolution in the deep convection parameterization, which has been coded to allow for these experiments. ${ }^{3}$ The changes in the parameterization for deep cumulus convection associated with the higher-resolution cloud model are summarized in section 3e of Donner et al. (2011). In addition, the least-entraining member of the cumulus ensembles in AM3-B and AM3-C occurs only $45 \%$ as frequently as in AM3-A and AM3-CTL, with an entrainment coefficient $54 \%$ larger.

We use several data sources for validation of our results. Two types of comparisons are conducted: (i) long-term climatological comparisons and (ii) comparisons of intraseasonal convective disturbances. Because the AM simulations are forced by $\sim 1980-2000$ seasonal cycle SSTs, we compare climatologies of simulated precipitation and 850-hPa zonal wind with 1980-2000 mean Global

\footnotetext{
${ }^{3}$ In Donner (1993), the cumulus cloud model [cf. Eqs. (5)-(7) therein] is solved on its own vertical grid (10-hPa resolution) to better capture the variations with height of the cumulus properties. The more computationally efficient version of the parameterization used in AM3, which instead uses the same vertical grid as AM3, was coded such that these experiments could more easily be done using the higher-resolution Donner (1993) version.
}

Precipitation Climatology Project (GPCP) (Adler et al. 2003) rainfall and interim European Centre for MediumRange Weather Forecasts Re-Analysis (ERA-Interim, hereafter abbreviated ERAI; Berrisford et al. 2009) winds.

The statistical behavior and physical structure of intraseasonal convective disturbances simulated by the AM2 and AM3 are compared with several validation datasets that span the 1999-2008 time window. Although this validation period is mostly outside of the 1980-2000 window used to construct the mean seasonal cycle SSTs that drive the AM simulations, it does allow us to utilize daily gridded precipitation products from the Tropical Rainfall Measuring Mission (TRMM) that are available only after late 1997. The 1999-2008 time window exhibits a slightly stronger El Niño SST pattern compared to the 1980-2000 window (not shown), but the differences are not substantial, and we believe that observed intraseasonal disturbances sampled from the 1999-2008 window are representative of the MJO. Total precipitation for the 1999-2008 period is taken from the TRMM 3B42 version 6 product, which blends spaceborne microwave and infrared retrievals and also scales the resulting 3 -h precipitation estimates to be consistent with monthly rain gauge measurements (Huffman et al. 2007). Outgoing longwave radiation (OLR) data are derived from the NOAA suite of polar orbiting satellites (Liebmann and Smith 1996). All remaining dynamic and thermodynamic variables are taken from ERAI. For a uniform comparison, all data are daily averaged, linearly interpolated to a $2.5^{\circ}$ horizontal grid, and resampled to the 27 ERAI standard pressure levels.

\section{Results}

\section{a. Global energy budget}

We examine the net energy budget at the earth's surface (SFC) and the top of the atmosphere (TOA) for 
TABLE 2. Global-mean energy budgets at the top of atmosphere (TOA) and earth surface (SFC) for observational estimates (Trenberth et al. 2009) and all AM2 and AM3 simulations. Observational estimates reported in Trenberth et al. (2009) are derived from satellite retrievals [Clouds and the Earth's Radiant Energy System (CERES), International Satellite Cloud Climatology Project (ISCCP), and GPCP], climate models [Community Land Model, version 3 (CLM3)], and various reanalysis products [e.g., National Centers for Environmental Prediction (NCEP); see Trenberth et al. (2009) for further details]. Net flux components are also shown, including shortwave (SW) and longwave (LW) radiation, surface latent heat flux ( $\mathrm{LH}$, includes column heating from snow formation), and surface sensible heat flux (SH). Positive fluxes are into the atmospheric column; units are watts per meter squared.

\begin{tabular}{|c|c|c|c|c|c|c|c|}
\hline & Obs & AM2-CTL & AM2-TOK & AM3-CTL & AM3-A & AM3-B & AM3-C \\
\hline & \multicolumn{7}{|c|}{ Time range } \\
\hline & 2000-04 & $10 \mathrm{yr}$ & $10 \mathrm{yr}$ & $10 \mathrm{yr}$ & $10 \mathrm{yr}$ & $10 \mathrm{yr}$ & $10 \mathrm{yr}$ \\
\hline & \multicolumn{7}{|c|}{ SFC } \\
\hline Net SW & -161.2 & -162.1 & -159.1 & -161.6 & -167.3 & -163.5 & -168.7 \\
\hline Net LH & +80.0 & +85.6 & +87.7 & +88.5 & +92.1 & +95.0 & +93.7 \\
\hline Net LW & +63.0 & +57.0 & +56.3 & +55.2 & +56.6 & +56.1 & +57.3 \\
\hline Net SH & +17.0 & +18.8 & +18.9 & +16.5 & +17.9 & +18.5 & +18.2 \\
\hline \multirow[t]{2}{*}{ NET SFC } & -0.9 & -0.7 & +3.7 & -1.4 & -0.7 & +6.2 & +0.6 \\
\hline & \multicolumn{7}{|c|}{ TOA } \\
\hline Net SW & +239.4 & +238.0 & +235.1 & +236.0 & +241.1 & +237.6 & +242.0 \\
\hline Net LW & -238.5 & -237.4 & -238.8 & -234.6 & -240.4 & -243.8 & -242.6 \\
\hline NET TOA & +0.9 & +0.6 & -3.8 & +1.4 & +0.7 & -6.2 & -0.6 \\
\hline NET column & 0.0 & -0.1 & -0.1 & 0.0 & 0.0 & 0.0 & 0.0 \\
\hline
\end{tabular}

observations and the AM simulations in Table 2. Only small differences in the net surface longwave and sensible heat fluxes are found between the different AM versions. Modifications of AM convective parameterizations examined in this study have a larger impact on net surface shortwave and latent heat fluxes. For example, globally averaged surface shortwave flux increases (becomes more negative, indicating a larger flux into the surface) but is partially compensated by an increase in latent heat flux. At the atmosphere top, the modified versions of the AM3 have enhanced net shortwave that is mostly offset by increased OLR. With the exception of AM3-B, net energy budget residuals at the SFC and TOA are less than $\left|4 \mathrm{~W} \mathrm{~m}^{-2}\right|$. All AM versions examined indicate net atmospheric column energy budget residuals less than about $\left|0.1 \mathrm{~W} \mathrm{~m}^{-2}\right|$.

\section{b. Boreal winter means}

Observed intraseasonal convective disturbances are influenced by the climatological state in which they exist (e.g., Hendon and Salby 1994). A review of many GCM simulations reveals that models with excessive mean precipitation in the equatorial west Pacific often generate larger intraseasonal precipitation variability (Slingo et al. 1996; Kim et al. 2011). Additionally, several GCM experiments indicate a link between the accurate depiction of tropical time-mean zonal winds and realistic MJO eastward propagation (Inness et al. 2003; Sperber at al. 2005). Figure 2 illustrates climatological boreal winter (November-April) precipitation for the 20-yr GPCP dataset (Fig. 2a) as well as the biases for all AM simulations (Figs. 2b-g). The AM2 and AM3 overestimate globally averaged annual precipitation by about $10 \%-$ $20 \%$. In the boreal winter, these biases are largest in the western Indian and Pacific Ocean basins, the Pacific intertropical convergence zone, and the South American west coast. A weak dry bias is noted near and west of Java in most AM simulations examined. In AM3-CTL, AM3-A, and AM3-C, a dry bias also appears in the equatorial west Pacific.

Recent analyses of global energy balances and cloud and aerosol properties based on the Cloud-Aerosol Lidar and Infrared Pathfinder Satellite Observations (CALIPSO), CloudSat, and Moderate Resolution Imaging Spectroradiometer (MODIS) satellites indicate that GPCP global mean precipitation could be biased low. Kato et al. (2011) show net surface irradiances consistent with global mean precipitation $15 \%-20 \%$ more than GPCP and still within estimated GPCP uncertainty (their Fig. 15). Accordingly, the precipitation overestimates relative to GPCP in AM2 and AM3, which increase in the modified AM3 versions examined in this study, may not be consequential.

A comparison of climatological boreal winter $850-\mathrm{hPa}$ zonal winds (hereafter, U850) between 1980-2000 ERAI and the 10-yr AM simulations (Fig. 3) indicates that AM2-CTL and AM3-CTL are able to reproduce the strip of equatorial low-level westerlies across the Indian Ocean, but that this region does not extend far enough into the west Pacific. For example, U850 westerlies extend to $175^{\circ} \mathrm{E}$ in ERAI but only to $135^{\circ}$ and $150^{\circ} \mathrm{E}$ in the AM3-CTL and 
Climatological November-April Rainfall
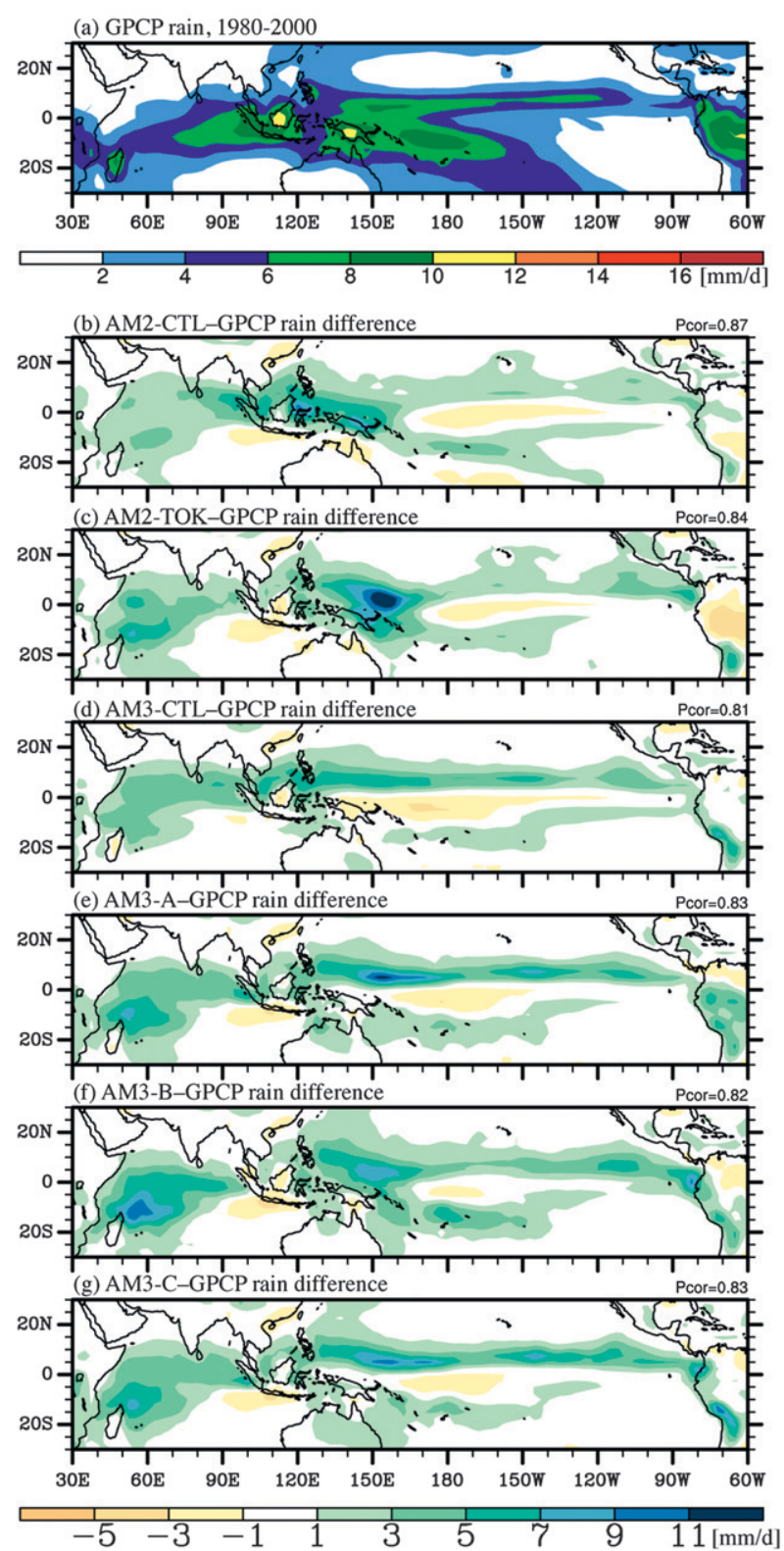

FIG. 2. (a) Boreal winter mean (November-April) GPCP precipitation (1980-2000) and (b)-(g) the difference in boreal winter mean precipitation between the GPCP dataset and each AM simulation. Pattern correlations for the domain $\left(20^{\circ} \mathrm{S}-20^{\circ} \mathrm{N}, 50^{\circ} \mathrm{E}-\right.$ $120^{\circ} \mathrm{W}$ ) are shown to the upper right of each difference panel.

AM2-CTL, respectively. The modified versions of the AM2 and AM3 tend to improve the eastward extension of low-level westerlies (e.g., to $160^{\circ} \mathrm{E}$ in AM2-TOK and $155^{\circ} \mathrm{E}$ in $\left.\mathrm{AM} 3-\mathrm{C}\right)$ but also underestimate their strength over the eastern Indian Ocean where magnitudes drop to less than $1 \mathrm{~m} \mathrm{~s}^{-1}$ as compared with $3-4 \mathrm{~m} \mathrm{~s}^{-1}$ in ERAI. In the extreme case, AM3-B actually produces U850 easterlies of $\sim 0.5 \mathrm{~m} \mathrm{~s}^{-1}$ over the eastern Indian

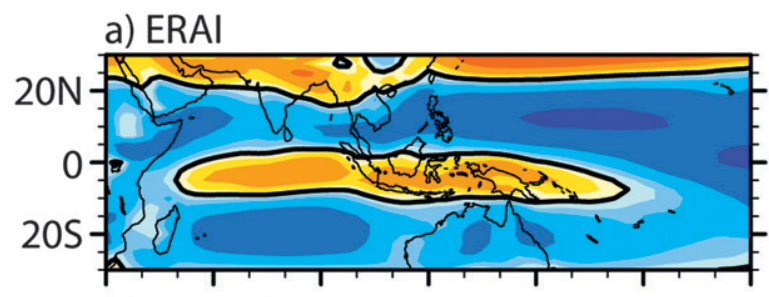

b) AM2-CTL

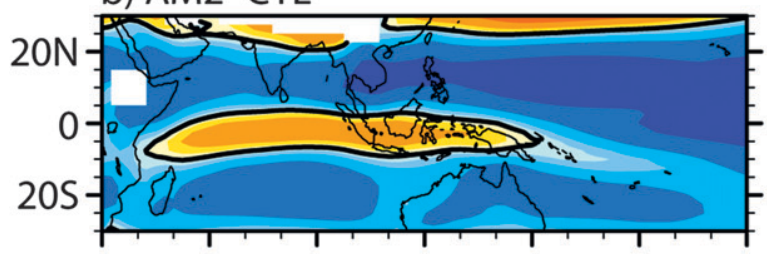

c) AM2-TOK

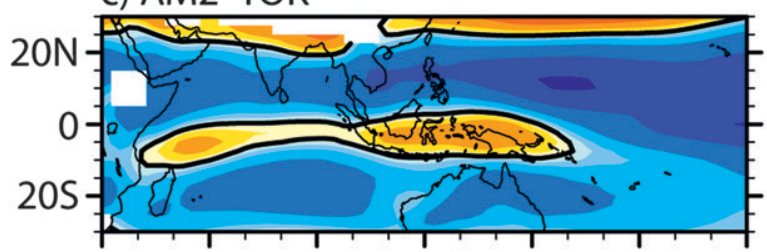

d) $\mathrm{AM} 3-\mathrm{CTL}$

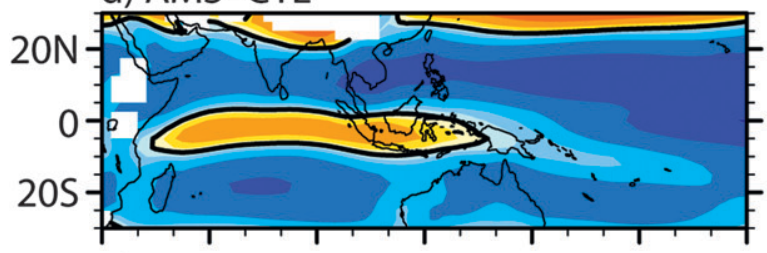

e) AM3-A

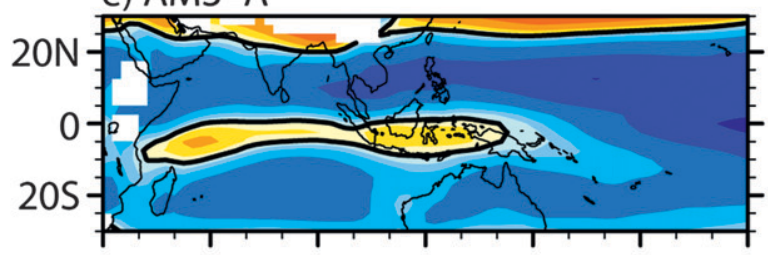

f) $\mathrm{AM} 3-\mathrm{B}$

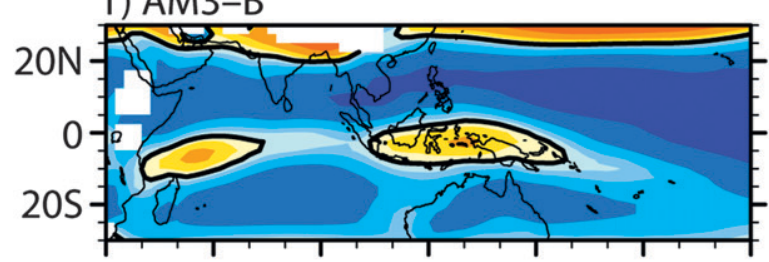

g) $\mathrm{AM} 3-\mathrm{C}$

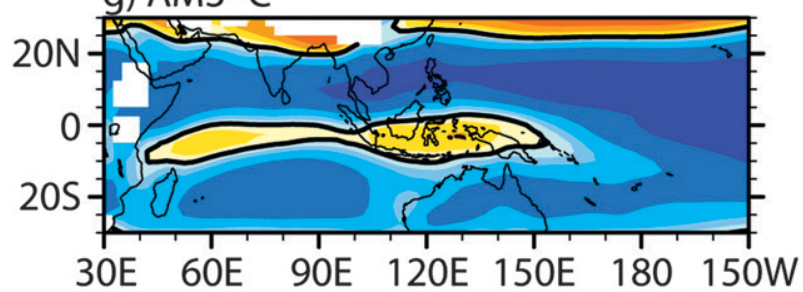

$\begin{array}{lllllllllll}-12 & -8 & -4 & -2 & -1 & 0 & 1 & 2 & 4 & 8 & 12[\mathrm{~m} / \mathrm{s}]\end{array}$

FIG. 3. Climatological boreal winter mean (November-April) 850-hPa zonal wind $U_{850}$ from (a) ERAI (1980-2000) and (b)-(g) the AM simulations analyzed. The zero contour is shown with a thick black line. 


\section{Climatological Relative Humidity Nov-Apr Average, $60^{\circ}-160^{\circ} \mathrm{E}$}

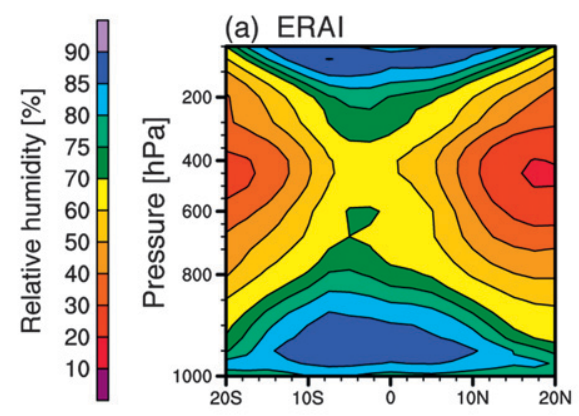

(b) AM2-CTL

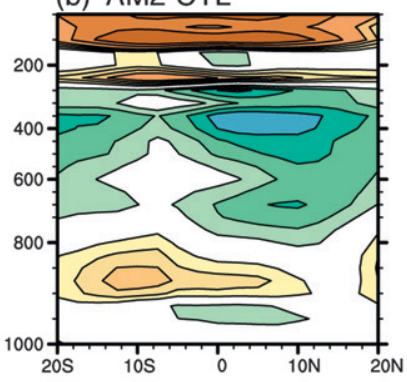

(c) AM2-TOK

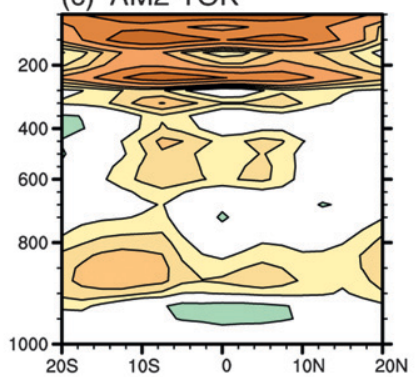

(d) AM3-CTL

(e) AM3-A

(f) $A M 3-B$
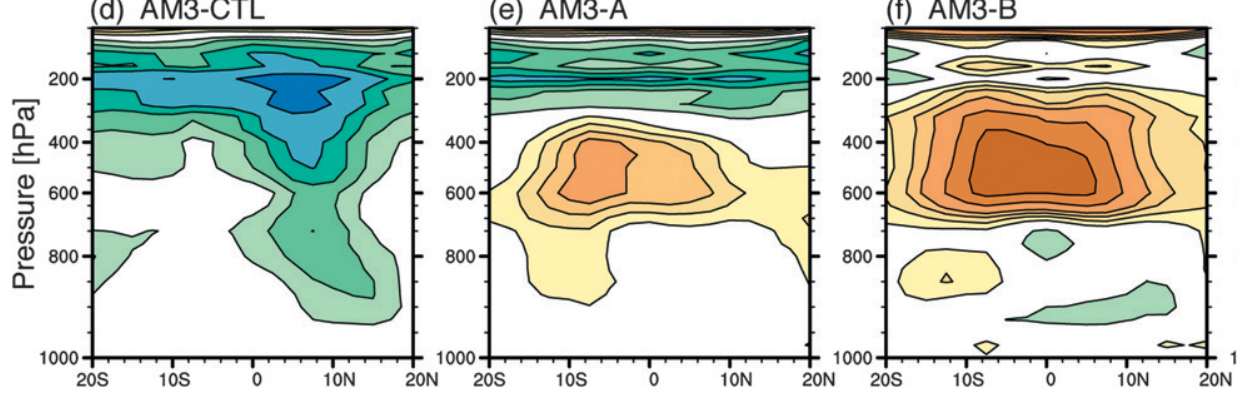

(g) AM3-C
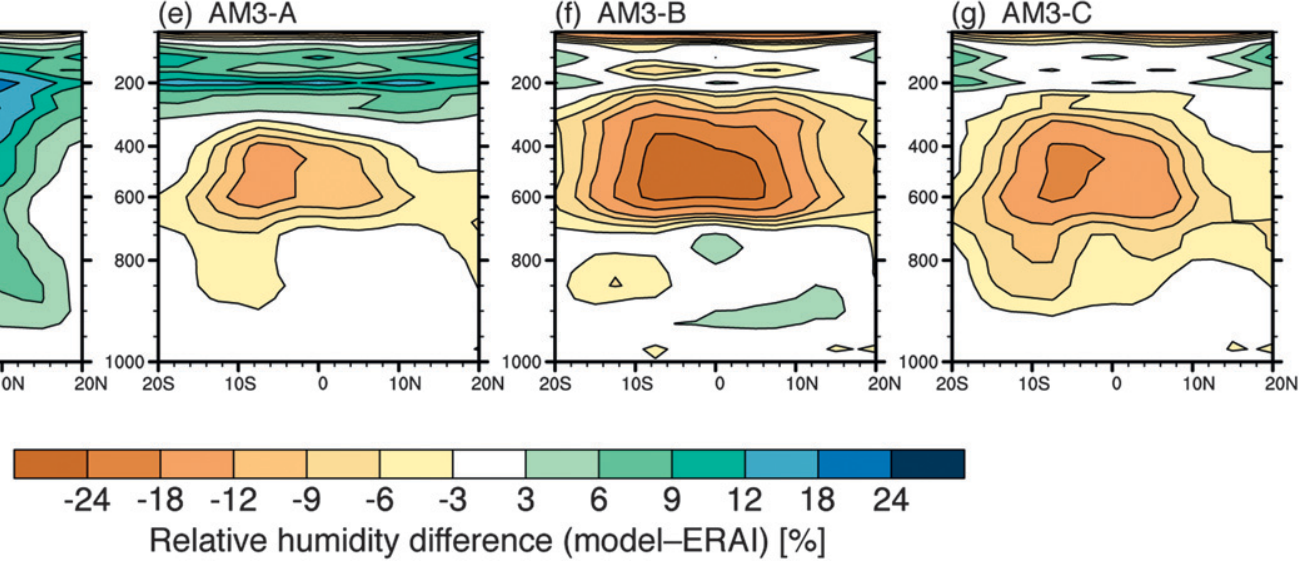

FIG. 4. Boreal winter mean (November-April) relative humidity averaged between $60^{\circ}$ and $160^{\circ} \mathrm{E}$ for (a) ERAI, and (b)-(g) the (model ERAI) humidity difference for each AM simulation.

Ocean (Fig. 3f). For all AM simulations, low-level boreal winter mean easterlies are too strong across southern Asia, the subtropical Pacific, and Central America.

Figure 4 shows boreal winter mean vertical profiles of relative humidity between $60^{\circ}$ and $160^{\circ} \mathrm{E}$ for ERAI and the humidity differences between each AM simulation and ERAI. Although only relative humidity profiles are displayed here, comments on other variables are included in this discussion. As documented in previous studies, the cool-troposphere and warm-stratosphere temperature biases in the AM2-CTL are reduced in the AM3-CTL (see middle column of Table 3; Anderson et al. 2004; Donner et al. 2011). Cool biases of $2-4 \mathrm{~K}$ in the middle to upper troposphere of the climatological deep convecting region $\left(10^{\circ} \mathrm{S}-5^{\circ} \mathrm{N}, 60^{\circ} \mathrm{E}-180^{\circ}\right)$ are evident in the AM2-TOK and all modified AM3 simulations, however, while tropical boundary layer temperatures are within a few tenths of a degree from the values indicated by ERAI (Table 3). Zero (for AM3) or weakly positive (for AM2) biases in boundary layer relative humidity are noted in Fig. 4. A moist bias above $500 \mathrm{hPa}$ in AM3-CTL (Fig. 4d) is strongly reduced and even reverses sign in the modified AM3 versions. For example, Fig. 4g shows relative humidity values that are nearly $20 \%$ lower than ERAI (Fig. 4a) in the equatorial midtroposphere. The cool and dry biases in the modified AM3 are likely linked to deep convection suppression that results from the changes made to the convective parameterization. Regarding vertical profiles of convective heating $Q_{1}$ [see Eq. (1) from Lin and Johnson (1996)] using identical

TABLE 3. Climatological November-April temperature biases for the AM simulations. Biases are computed as the simulation differences from reanalysis, averaged horizontally within the region $\left(10^{\circ} \mathrm{S}-5^{\circ} \mathrm{N}, 60^{\circ} \mathrm{E}-180^{\circ}\right)$ and vertically within the noted pressure levels.

\begin{tabular}{lcc}
\hline \hline & \multicolumn{2}{c}{ Averaged $T$ bias $(\mathrm{K})$} \\
\cline { 2 - 3 } Simulation & $200-500 \mathrm{hPa}(8$ levels $)$ & $900-1000 \mathrm{hPa}(5$ levels $)$ \\
\hline AM2-CTL & -1.79 & +0.01 \\
AM2-TOK & -3.85 & -0.03 \\
AM3-CTL & +0.22 & +0.18 \\
AM3-A & -2.17 & +0.32 \\
AM3-B & -2.24 & -0.10 \\
AM3-C & -3.49 & +0.31
\end{tabular}


space-time averaging as in Fig. 4, the levels and magnitudes of maximum heating among the reanalysis and AM simulations are qualitatively similar. ${ }^{4}$ One exception is that the maximum of November-April mean heating shifts from the Northern Hemisphere $\left(5^{\circ} \mathrm{N}\right)$ in AM3-CTL to the Southern Hemisphere $\left(2.5^{\circ} \mathrm{S}\right)$ in all modified versions of AM3 (not shown). All AM simulations tend to overestimate heating and rising motion north of the equator and underestimate heating south of the equator during boreal winter. A persistent and unrealistic secondary maximum of convective heating near $125 \mathrm{hPa}$ is also noted in the $\mathrm{AM}$ within $10^{\circ}$ of the equator (not shown).

\section{c. Zonal wavenumber-frequency spectra}

Decomposing a total field into its zonal wavenumber and frequency components allows a succinct view of tropical wave activity. We compute such spectra for the AM2 and AM3 output data using the methods of Wheeler and Kiladis (1999). Figure 5 depicts power spectra of the symmetric component of tropical precipitation for observations and a selection of AM simulations. Figures $5 \mathrm{a}-\mathrm{f}$ each consist of a pair of plots showing the base- 10 logarithm of the summation of spectral power from $15^{\circ} \mathrm{S}$ to $15^{\circ} \mathrm{N}$ ("raw" spectrum, top) and the raw spectrum divided by a smoothed background spectrum ("significant" spectrum, bottom). Negative zonal wavenumbers are associated with disturbances that propagate westward and positive wavenumbers with those that propagate eastward. Figure 6 shows the same spectra as Fig. 5 but zoomed into the MJO spectral region. Relative to the AM2-CTL (not shown), AM2-TOK exhibits a shift of the maximum intraseasonal power from westward to eastward propagating disturbances but continues to lack Kelvin wave activity that is prevalent in nature (Fig. 5a). As in AM2-TOK, previous modeling studies have also reported that MJO variability generally becomes more realistic through the use of stronger moisture triggers-more stringent requirements for high humidity to be present in some layer in order for parameterized deep convection to occur-in the deep convection parameterization (e.g., Lin et al. 2008). Stronger triggers were found to increase the contributions of largescale condensation, making model convection more sensitive to environmental moisture. Lin et al. attribute the slower and more intense disturbances to a reduction in gross moist stability, as was demonstrated in earlier studies using an idealized moist GCM (Frierson 2007).

\footnotetext{
${ }^{4}$ The accuracy of computing the pressure level of peak convective heating is complicated by the model's vertical resolution in the midtroposphere. Approximate layer-midpoint pressures in this area are 392, 461, 532, and $600 \mathrm{hPa}$.
}

The modifications made to the AM3 convective parameterization generally have a positive impact on the depiction of tropical precipitation variability relative to the control simulation, at the expense of a degraded mean state as seen in Fig. 2 and noted in Donner et al. (2011). Implementation of a modified convective closure (Zhang 2002) and trigger (Donner et al. 2001) dramatically improves precipitation variability associated with Kelvin waves, the MJO, inertio-gravity waves (e.g., Figs. 5d and 6d), and mixed Rossby-gravity waves (not shown) compared to AM3-CTL (Fig. 5c). Consistent with Fig. 5, maps of variance of MJO-filtered precipitation (not shown) show a marked improvement for the modified AM3 compared to AM3-CTL despite an overestimation of variability in the Northern Hemisphere ITCZ. As in the case of AM2, the peak in intraseasonal power shifts from a westward to eastward propagation preference in AM3 when a convective parameterization that suppresses deep cumuli is implemented. In the antisymmetric precipitation spectra (not shown), modified AM3 versions have improved (larger) power in the MJO region but the signal-to-noise ratio is not significant. Despite these improvements, several differences between the observed and modified AM3 precipitation spectra are evident. Overall, total variance is overestimated in the modified versions of AM3, consistent with the findings of Kim et al. (2011). Raw power for westward propagating disturbances on subseasonal time scales ( $\sim 6-90$ days) is overestimated as well. The power within the MJO spectral region (zonal wavenumbers +1 to +5 , periods 20-90 days) is also moderately overestimated and exhibits a maximum closer to a 25-35-day period compared to the observed $\sim 45$ day period (Fig. 6 , see Table 4 ). Additionally, the significant spectra show that Kelvin wave power shifts to smaller equivalent depths (slower phase speeds) and lower frequencies in the AM3 simulations that incorporate more stringent convective triggers (Figs. 5d,e), in agreement with Frierson et al. (2011). In AM3-C, low-frequency eastward propagating disturbances resemble convectively coupled Kelvin waves rather than the MJO, as is shown here in Figs. 5 and 6 (and later in Fig. 8). The ability of AM3-A to simulate the combination of equatorial Rossby and Kelvin waves and MJO disturbances makes it an appealing test bed for future studies of tropical intraseasonal variability.

Recent work by Roundy (2012a,b) suggests that in nature there is a smooth transition of spectral power between the $\mathrm{MJO}$ and Kelvin bands in regions of climatological lowlevel westerlies, in contrast to the spectral gap that arises within the dominant easterly trade regime. In the modified AM3, Kelvin power shifts to lower frequencies and smaller equivalent depths (slower phase speeds) and the 

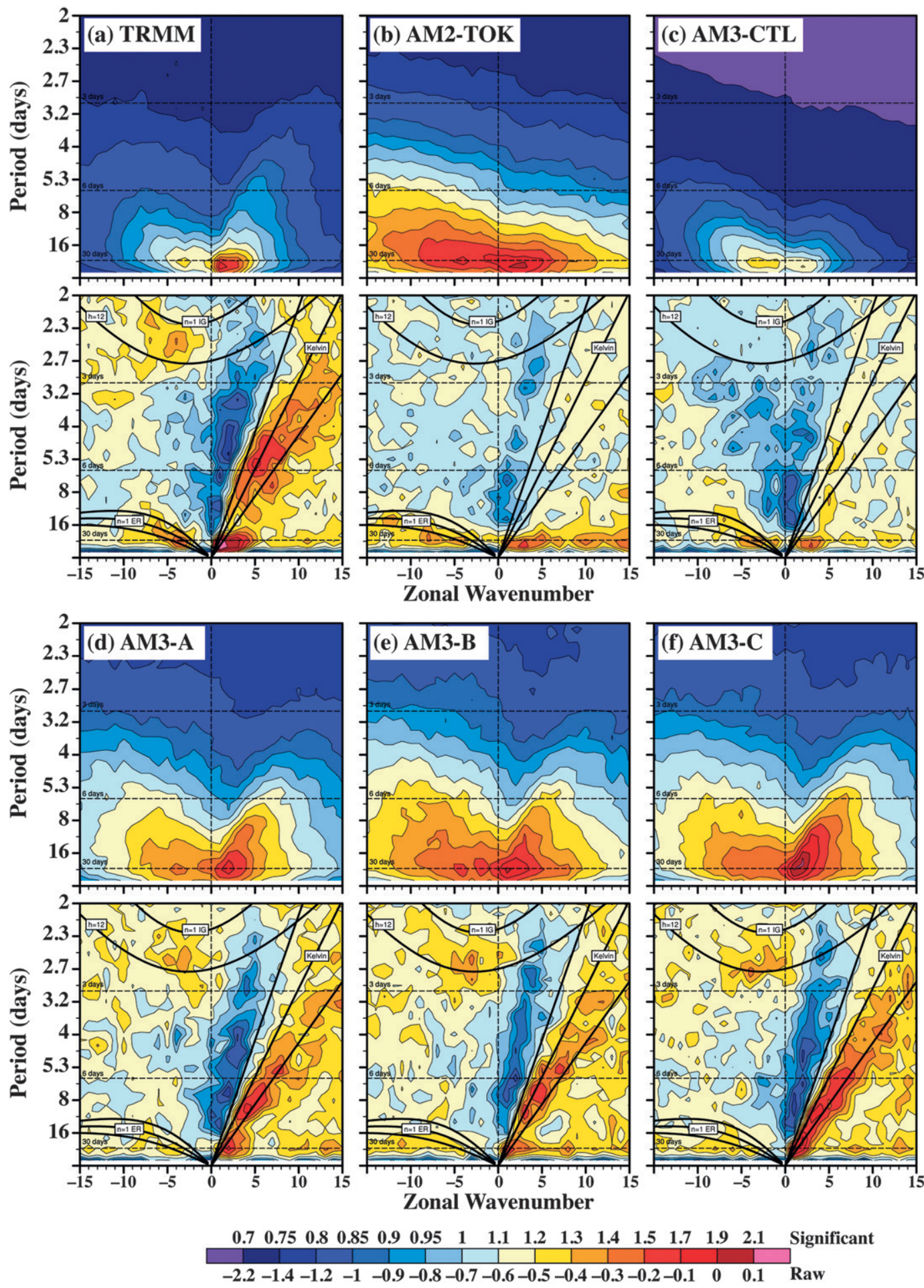

FIG. 5. Frequency-zonal wavenumber power spectra of the symmetric component (about the equator) of precipitation for observations and a selection of AM simulations. For each panel, a pair of plots display the (top) base-10 logarithm of the summation of power between $15^{\circ} \mathrm{S}$ and $15^{\circ} \mathrm{N}$ (raw spectrum) and (bottom) raw spectrum divided by a smoothed background spectrum. Thick black lines represent dispersion curves for equivalent depths of 12,25 , and $50 \mathrm{~m}$ for equatorial Rossby (ER), Kelvin, and eastward and westward inertio-gravity waves (EIG and WIG, respectively) and the MJO. Negative zonal wavenumbers correspond to westward propagation. 

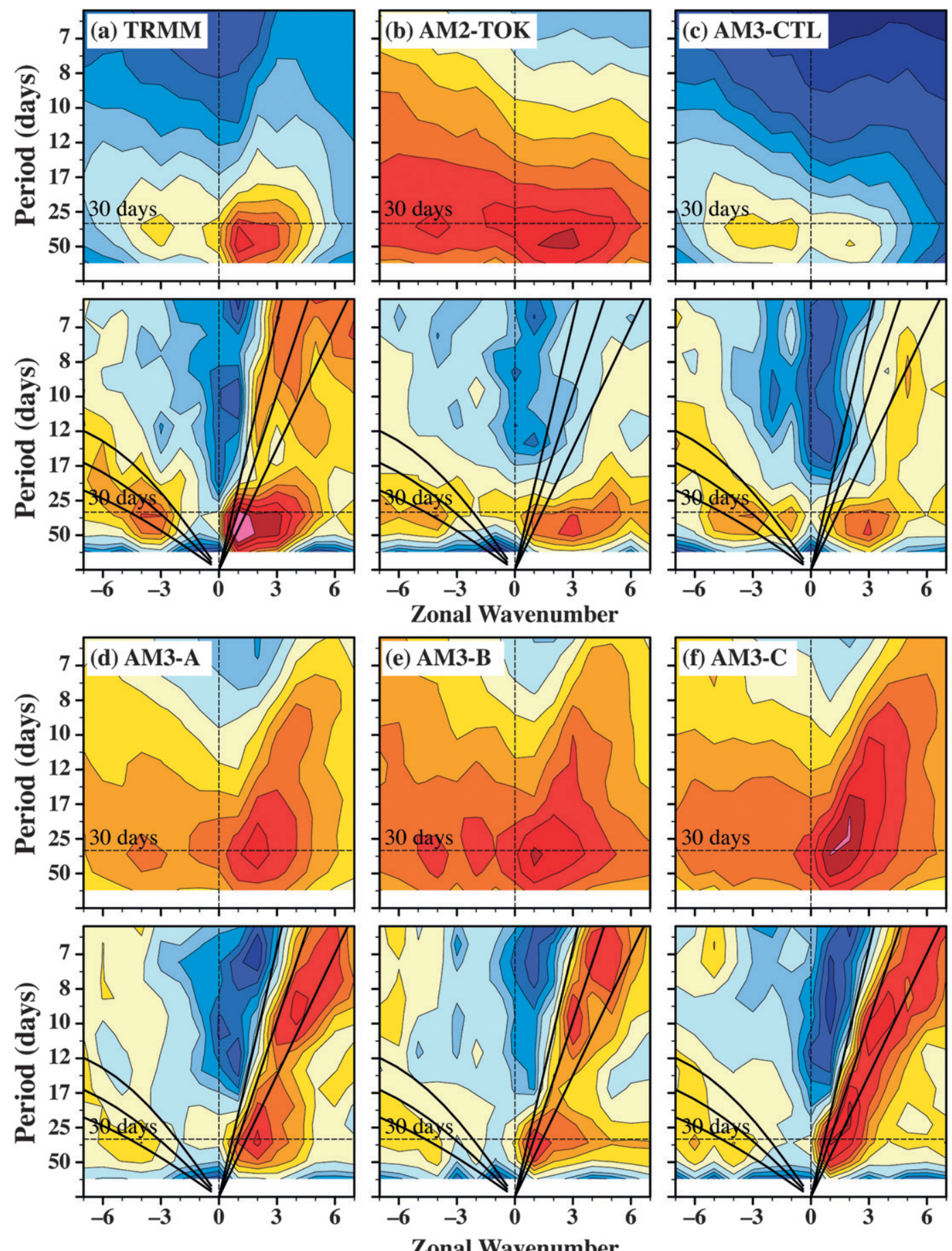

$\begin{array}{llllllllllllllll}0.7 & 0.75 & 0.8 & 0.85 & 0.9 & 0.95 & 1 & 1.1 & 1.2 & 1.3 & 1.4 & 1.5 & 1.7 & 1.9 & 2.1 & \text { Significant }\end{array}$

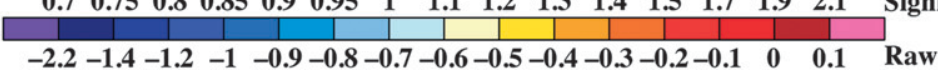

FIG. 6. As in Fig. 5 but zoomed in to the MJO spectral region.

gap between MJO and Kelvin spectral peaks is less noticeable, particularly for AM3-C. However, the low-level westerlies - the presence of which contribute to the smooth MJO-Kelvin transition in Roundy (2012b) - are weaker in the modified AM3 compared to AM3-CTL (cf. Fig. 3), and the smooth MJO-Kelvin transition follows the $h=12 \mathrm{~m}$ shallow water equivalent depth line rather than $h=5 \mathrm{~m}$ as in Roundy (2012b). 
TABLE 4. Summary of intraseasonal convective disturbances and warm pool mean state biases for ERAI and the AM simulations. Columns include U850 (qualitative bias description and eastward extent of boreal winter mean $U_{850}$ equatorial westerlies), RH [relative humidity bias description in the upper and middle troposphere (approximately 200-400 hPa and 400-600 hPa, respectively) and boundary layer (BL; 900-1000 hPa)], T (temperature bias description), MJO E/W [ratio of eastward to westward spectral power for the symmetric component of precipitation in the MJO spectral region (periods 32-96 days, zonal wavenumbers from +1 to +3 (eastward) or from -1 to -3 (westward)], Kelvin (qualitative comparison of Kelvin waves between simulation and reanalysis based on significant power spectra in Fig. 5), MJO [qualitative MJO comparison between simulations and reanalysis based on significant power spectra in Fig. 6, where the approximate zonal wavenumber (zwn) and period $(t)$ of the peak power are indicated], and Speed (approximate intraseasonal disturbance phase speed based on Fig. 8). Other abbreviations in the table include IO (Indian Ocean), WP (west Pacific), and trop (troposphere).

\begin{tabular}{|c|c|c|c|c|c|c|c|}
\hline & \multicolumn{3}{|c|}{ Boreal winter mean biases } & \multicolumn{4}{|c|}{ Intraseasonal disturbances } \\
\hline & $U_{850}$ & RH & $T$ & $\begin{array}{l}\mathrm{MJO} \\
\mathrm{E} / \mathrm{W}\end{array}$ & Kelvin & MJO & $\begin{array}{c}\text { Speed } \\
\left(\mathrm{m} \mathrm{s}^{-1}\right)\end{array}$ \\
\hline ERAI & $175^{\circ} \mathrm{E}$ & - & - & 2.4 & - & - & $5-6$ \\
\hline AM2-CTL & Realistic, $150^{\circ} \mathrm{E}$ & $\begin{array}{l}\text { Up-trop: dry } \\
\text { Mid-trop: moist } \\
\text { BL: moist }\end{array}$ & Mid-trop: cool & 0.9 & Very weak & zwn $2-3, t \sim 45 \mathrm{~d}$ & - \\
\hline AM2-TOK & $\begin{array}{l}\text { Weak IO, realistic } \\
\text { WP }, 160^{\circ} \mathrm{E}\end{array}$ & $\begin{array}{l}\text { Up-trop: dry } \\
\text { Mid-trop: dry } \\
\text { BL: moist }\end{array}$ & $\begin{array}{l}\text { Mid-trop: very } \\
\text { cool }\end{array}$ & 1.4 & Very weak & zwn $3, t \sim 45 \mathrm{~d}$ & 5 \\
\hline AM3-CTL & Realistic, $135^{\circ}$ & Up-trop: moist & Small $T$ biases & 0.9 & Weak & zwn $3, t \sim 45 \mathrm{~d}$ & - \\
\hline AM3-A & Weak, $140^{\circ} \mathrm{E}$ & $\begin{array}{l}\text { Up-trop: moist } \\
\text { Mid-trop: dry }\end{array}$ & $\begin{array}{l}\text { Mid-trop: cool } \\
\text { BL: warm }\end{array}$ & 1.5 & Slow & zwn $2, t \sim 30 \mathrm{~d}$ & $6-10$ \\
\hline AM3-B & $\begin{array}{l}\text { Very weak } \\
\quad \text { (IO easterlies), } \\
160^{\circ} \mathrm{E}\end{array}$ & Mid-trop: very dry & Mid-trop: cool & 1.4 & Slow & zwn $1, t \sim 35 \mathrm{~d}$ & $5-7$ \\
\hline AM3-C & Weak, $155^{\circ} \mathrm{E}$ & Mid-trop: dry & $\begin{array}{l}\text { Mid-trop: very } \\
\text { cool } \\
\text { BL: warm }\end{array}$ & 1.6 & $\begin{array}{l}\text { Slow, merged } \\
\text { with MJO } \\
\text { signal }\end{array}$ & zwn $1-2, t \sim 20-30 \mathrm{~d}$ & $6-11$ \\
\hline
\end{tabular}

We present zonal wavenumber-frequency spectra of U850 for ERAI, AM2-TOK, and AM3-C in Figs. 7a-c, respectively. Both AM2 and AM3 generate zonal wind variability associated with equatorial Rossby and Kelvin waves and the MJO, but several biases exist. AM2-CTL and AM3-CTL underestimate power for low-frequency Kelvin waves and the MJO (not shown). All AM simulations overestimate zonal wind variability in the spectral area where high-frequency Kelvin waves merge with eastward inertia-gravity waves. AM2-TOK produces Kelvin waves with much higher phase speeds (larger equivalent depths) relative to ERAI, likely due to the absence of sufficient convective coupling (cf. Figs. 7a,b). A persistent bias of the AM3 is the enhanced zonal wind variability of low-frequency Kelvin waves that is evident when the background spectrum is removed (bottom plot of Fig. 7c). The clear separation of zonal wind spectral power between the MJO and low-frequency Kelvin waves near a 16-day period in ERAI (Fig. 7a) is seen in AM2-TOK (Fig. 7b) but not in any of the AM3 simulations (e.g., Fig. 7c; AM3-A and AM3-B U850 spectra are qualitatively similar to AM3-C and so are omitted from Fig. 7). The absence of an MJO-Kelvin spectral gap in U850 occurs despite no enhancement of climatological low-level westerlies over the Indo-Pacific region in the AM3 compared to AM2 (see Roundy 2012b).
Modified versions of the AM3 do, however, produce slower and more realistic Kelvin wave phase speeds, suggesting an improvement in the coupling between tropical convection and dynamics in AM3. A reduction in Kelvin wave phase speed is noted when the dilute CAPE approximation is implemented in the AM3, compared to the nondilute CAPE case. The dilute CAPE approach is assumed to represent a more inhibiting convective trigger in that, relative to the undiluted CAPE case, more instability is required to reach the CAPE threshold for deep convection $\left(1000 \mathrm{~J} \mathrm{~kg}^{-1}\right)$. Our findings support the conclusions of Frierson (2007) and Frierson et al. (2011), who showed that slower Kelvin waves developed with more inhibiting convective triggers due to a reduction in gross moist stability.

\section{d. Lag correlation}

We present lag correlations between rainfall and U850 in Fig. 8. To construct these plots, we first apply a 20-100day bandpass filter to anomalous precipitation and U850, where the anomaly is a departure from the smoothed calendar-day mean at each grid point. The data are then latitudinally averaged between $15^{\circ} \mathrm{S}$ and $15^{\circ} \mathrm{N}$. We correlate the time series of precipitation at either $90^{\circ} \mathrm{E}$ or $150^{\circ} \mathrm{E}$ (left and right columns of Fig. 8, respectively) with U850 over a range of time lags and longitudes. Results 

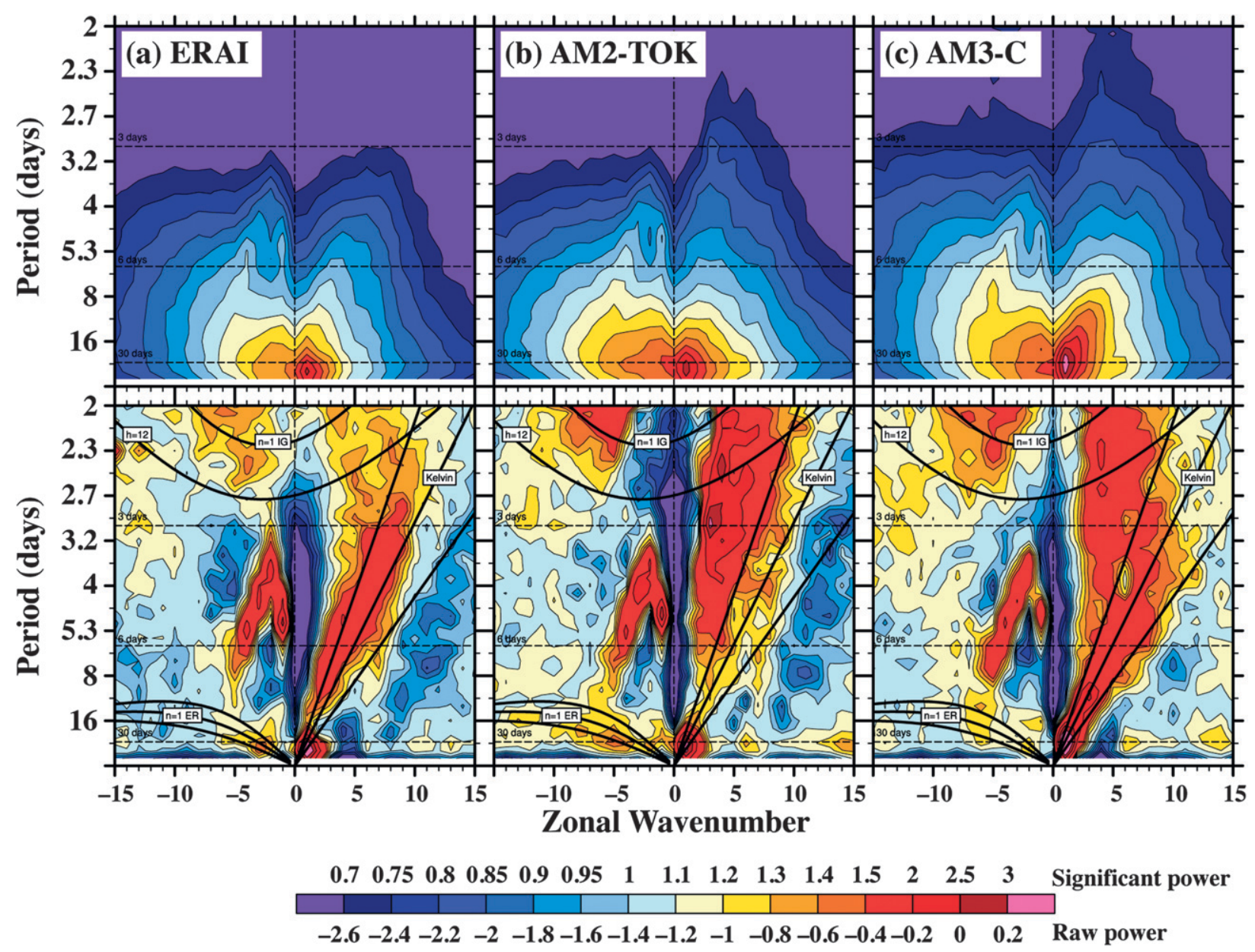

FIG. 7. As in Fig. 5 but for 850-hPa zonal winds for (a) ERAI, (b) AM2-TOK, and (c) AM3-C.

from the AM2-CTL and AM3-CTL are not shown owing to the inability of those models to produce realistic eastward-propagating intraseasonal convection. Among the modified AM simulations shown, the coupling between rainfall (which is approximately proportional to the vertically integrated diabatic heating) and U850 (which we take to be largely a dynamical response to the diabatic heating) is stronger in the AM3-A and AM3-C. Although AM2-TOK produces realistic phase speeds for disturbances in the west Pacific, it has difficulty depicting a strong signal in the Indian Ocean (cf. Figs. 8c,d). The modified AM2 and AM3 simulations tend to have a stationary or westward-moving U850 signal to the west of the regression base point at $90^{\circ} \mathrm{E}$ (Fig. 8, left column), in contrast to reanalysis. The signal generated by AM3-A in the Indian Ocean (Fig. 8e) suggests that this model is able to simulate MJO phase speeds in that region better than AM3-B and AM3-C. However, a general tendency exists for disturbances in the modified AM3 simulations to propagate too quickly, particularly when deep convection is moving across the west Pacific region. For example, estimated phase speeds in the west Pacific are about $5 \mathrm{~m} \mathrm{~s}^{-1}$ in AM2-TOK but closer to $11 \mathrm{~m} \mathrm{~s}^{-1}$ in AM3-C (see Table 4). This rapid propagation of convective disturbances in the modified AM3 may be partially attributed to the use of prescribed SSTs in the model. More realistic air-sea interactions, even in an idealized framework, have been shown to reduce the phase speed and enhance organization of the MJO in some GCMs (Zhang et al. 2006). The faster speeds in the AM3-C are consistent with the poorly distinguished separation between the MJO and Kelvin spectral peaks in Figs. $6 f$ and $7 \mathrm{c}$ and suggest that, particularly in the Pacific, the disturbances produced by the modified AM3 versions have characteristics more reminiscent of low-frequency convectively coupled Kelvin waves (Straub et al. 2010). This assertion is supported by noting that, in the modified AM3, the pattern of low-level zonal wind anomalies differs from the observed MJO pattern in the Pacific (Fig. 8b) such that a negative correlation exists between intraseasonal rainfall and U850, and peak low-level easterlies occur only a few days before the precipitation 
(a) OBS, $90^{\circ} \mathrm{E}$

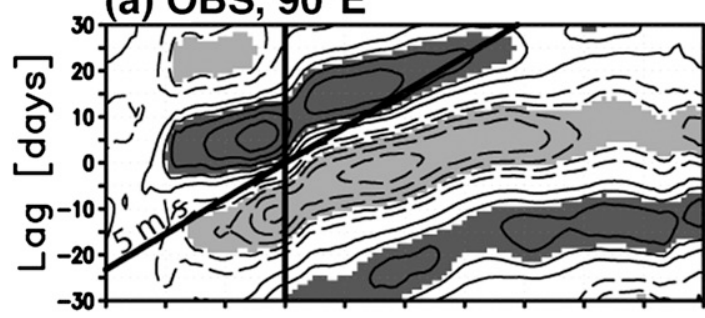

(c) AM2-TOK, $90^{\circ} \mathrm{E}$

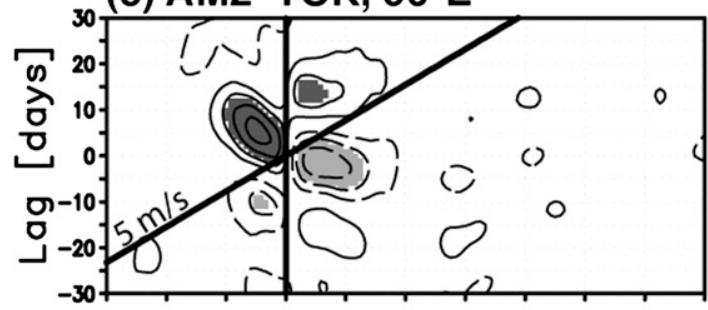

(e) AM3-A, $90^{\circ} \mathrm{E}$

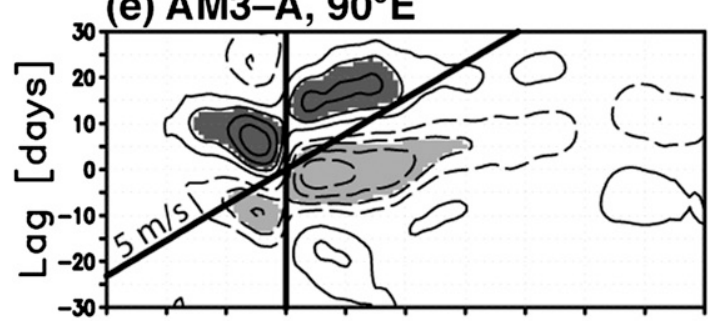

(g) AM3-B, $90^{\circ} \mathrm{E}$
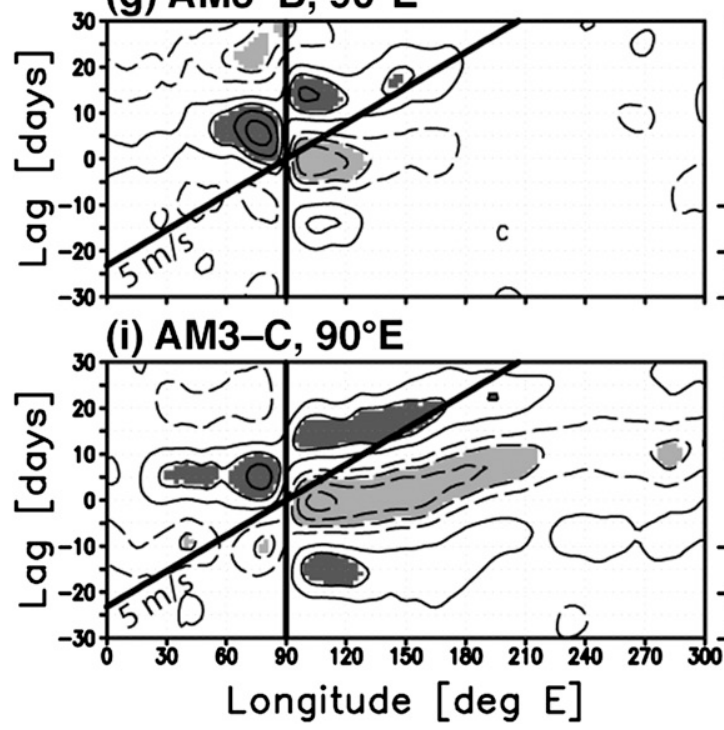

(b) OBS, $150^{\circ} \mathrm{E}$

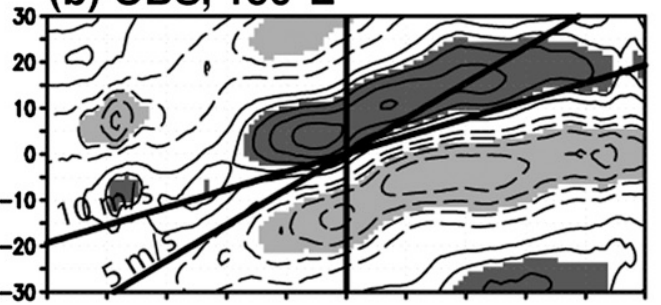

(d) AM2-TOK, $150^{\circ} \mathrm{E}$

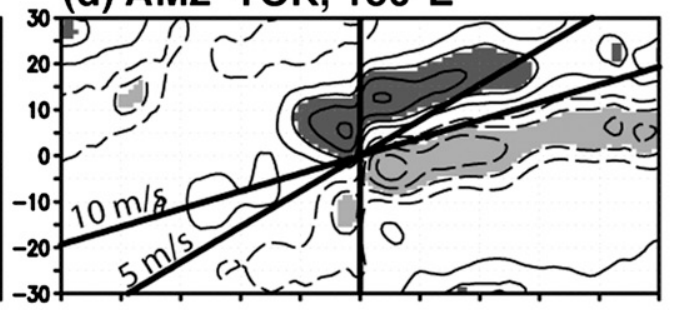

(f) AM3-A, $150^{\circ} E$

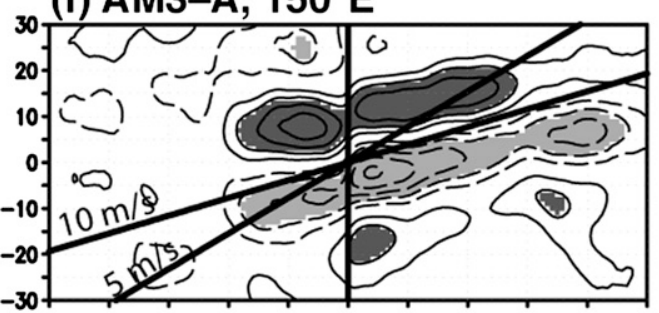

(h) AM3-B, $150^{\circ} \mathrm{E}$

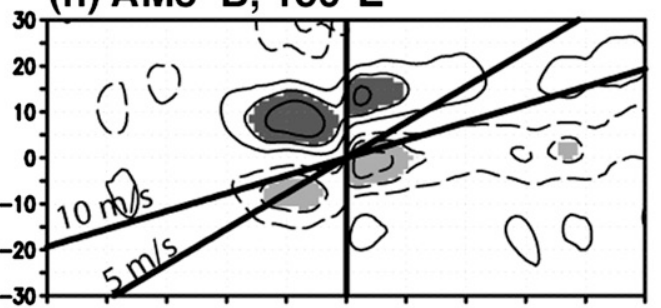

(j) AM3-C, $150^{\circ} \mathrm{E}$

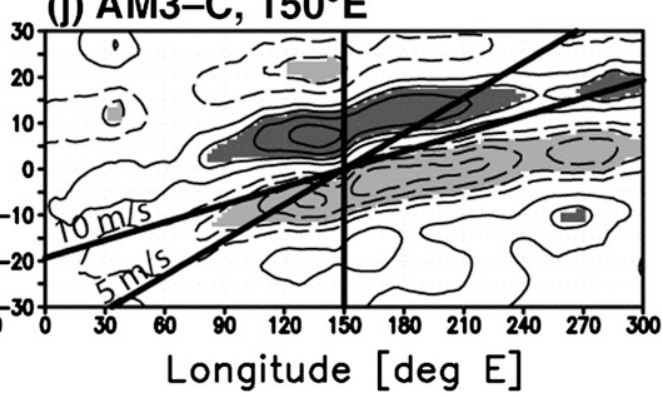

FIG. 8. Lag correlations of 850 -hPa zonal wind $U_{850}$ with precipitation at (left) $90^{\circ} \mathrm{E}$ and (right) $150^{\circ} \mathrm{E}$. Both fields are bandpass filtered (20-100 days) and averaged between $15^{\circ} \mathrm{S}$ and $15^{\circ} \mathrm{N}$. Solid (dashed) contours represent positive (negative) correlations that are shaded dark (light) gray if they exceed the 95\% statistical significance level. We use ERAI and TRMM for the observed wind and rainfall fields. In the left panels, the index reference longitudes and the $5 \mathrm{~m} \mathrm{~s}^{-1}$ phase speed are marked by vertical and slanted thick lines, respectively. The right panels also contain the $10 \mathrm{~m} \mathrm{~s}^{-1}$ phase speed line.

maximum (Figs. 8f,h,j). This structure is more consistent with observed convectively coupled Kelvin waves (Wheeler et al. 2000) than with the MJO (Kiladis et al. 2005; Benedict and Randall 2007).

\section{e. Lag regression}

We present longitudinal cross sections of specific humidity for ERAI and several AM simulations in Fig. 9. 
(a) OBS, $90^{\circ} \mathrm{E}$

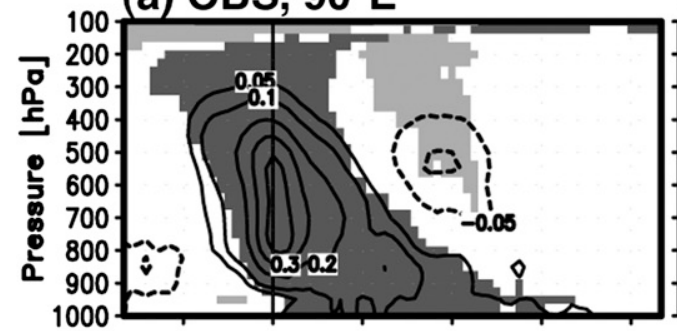

(c) AM2-TOK, $90^{\circ} \mathrm{E}$

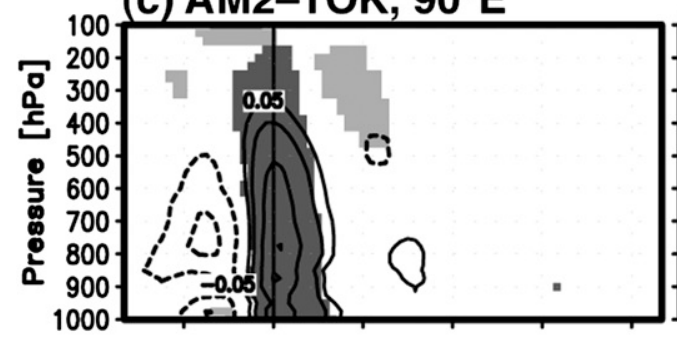

(e) AM3-A, $90^{\circ} \mathrm{E}$
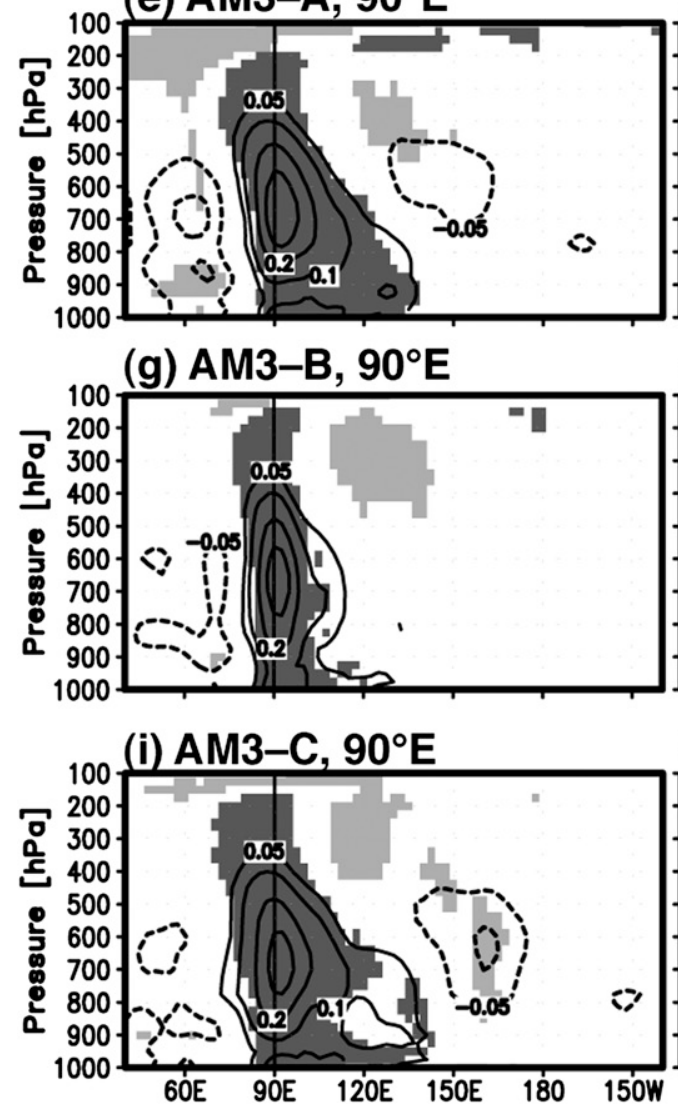

(b) $\mathrm{OBS}, 150^{\circ} \mathrm{E}$

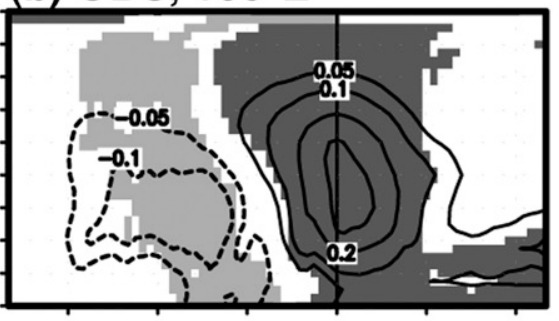

(d) AM2-TOK, $150^{\circ} \mathrm{E}$

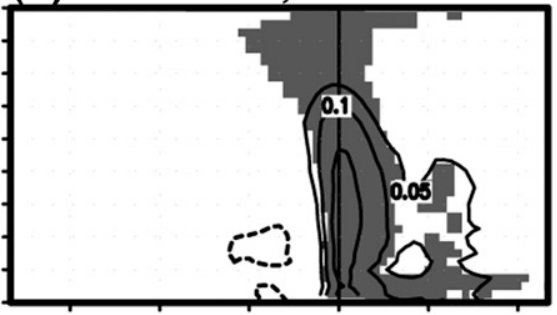

(f) $A M 3-A, 150^{\circ} E$

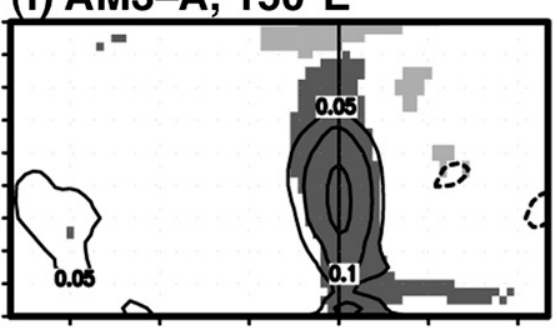

(h) $A M 3-B, 150^{\circ} E$

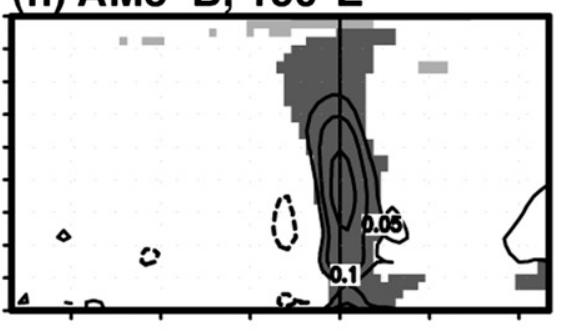

(j) AM3-C, $150^{\circ} \mathrm{E}$

FIG. 9. Lag-0 longitudinal cross sections of specific humidity anomalies linearly regressed onto a standardized 20-100-day filtered precipitation index time series at (left) $90^{\circ} \mathrm{E}$ and (right) $150^{\circ} \mathrm{E}$. Humidity anomalies are departures from a smoothed calendar-day mean, and anomaly values represent a one standard deviation change in the index. Both fields are averaged between $15^{\circ} \mathrm{S}$ and $15^{\circ} \mathrm{N}$. Positive (negative) anomalies that exceed the $95 \%$ statistical significance levels are shaded dark (light) gray. We use ERAI and TRMM for the observed specific humidity and rainfall fields. Index reference longitudes are marked by thick vertical lines. Contour interval is $\pm 0.1 \mathrm{~g} \mathrm{~kg}^{-1}$, and the $\pm 0.05 \mathrm{~g} \mathrm{~kg}^{-1}$ contour is also shown. No zero contour is drawn. 
(a) OBS $Q_{1}$

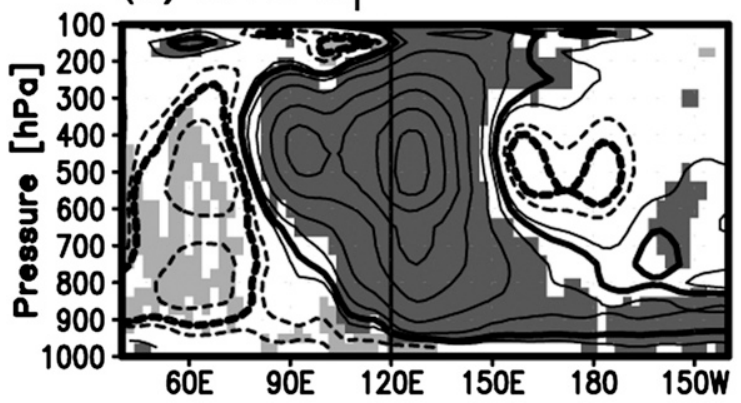

(c) AM3-B $Q_{1}$

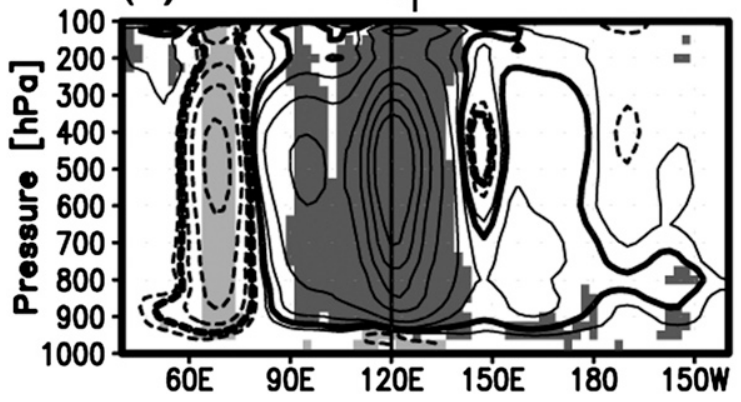

(b) AM3-A $Q_{1}$

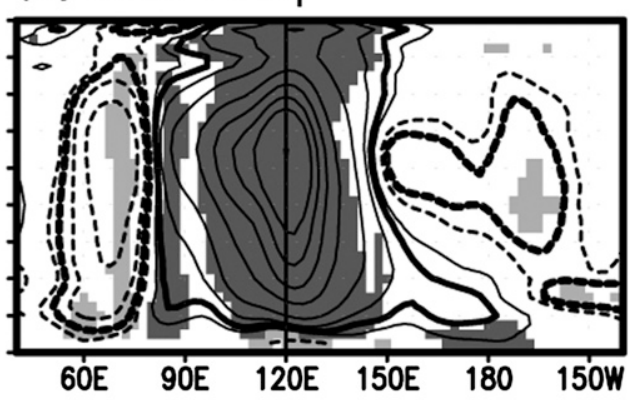

(d) AM3-C $Q_{1}$

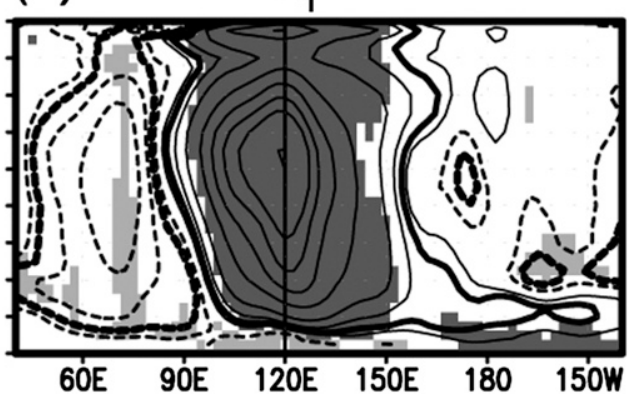

FIG. 10. As in Fig. 9 but for anomalous apparent convective heat source $Q_{1}$ linearly regressed onto 20-100-day filtered precipitation at $120^{\circ} \mathrm{E}$. All fields are averaged between $5^{\circ} \mathrm{S}$ and $5^{\circ} \mathrm{N}$. Contours are $\pm 0.025,0.05,0.1,0.2,0.4$, $0.6,0.8$, and $1.0 \mathrm{~K} \mathrm{day}^{-1}$, with a contour interval of $\pm 0.5 \mathrm{~K}$ day $^{-1}$ for more extreme values. The $\pm 0.05 \mathrm{~K} \mathrm{day}^{-1}$ contours are emboldened, and a 7-point weighted running mean has been applied in longitude to clarify heating patterns.

Anomalous specific humidity is linearly regressed onto a standardized version of the precipitation index defined in section $3 \mathrm{~d}$ and then averaged between $15^{\circ} \mathrm{S}$ and $15^{\circ} \mathrm{N}$. Plotted values represent humidity anomalies associated with a one standard deviation change in the precipitation index at zero time lag. All modified AM versions underpredict the longitudinal extent and maximum value of positive humidity anomalies relative to ERAI. The longitudinal structure of moisture appears to be strongly associated with the ability of the AM to realistically simulate eastward propagation of intraseasonal convective systems, as seen in Fig. 8. In particular, the models that perform best at producing these disturbances (Figs. 9d,e,i,j) show some evidence of shallow moistening that leads deep moistening. Low-level moistening leading deep moistening is apparent in the ERAI results (Figs. 9a,b) and in previous reanalysis- and radiosonde-based studies of the observed MJO (Kiladis et al. 2005; Kemball-Cook and Weare 2001) and other convectively coupled equatorial waves (Kiladis et al. 2009).

Regression cross sections of convective heating $Q_{1}$ for ERAI and modified AM3 versions are shown in Fig. 10. We use a precipitation index based at $120^{\circ} \mathrm{E}$ and a $5^{\circ} \mathrm{S}-5^{\circ} \mathrm{N}$ latitude band to best display the vertically tilted heating profile in ERAI (Fig. 10a)..$^{5}$ Although the overall width of positive heating is qualitatively correct in the AM3, all simulations produce a deep heating core that is too narrow and intense (by about $10 \%-20 \%$ ) compared to ERAI. Additionally, the vertical gradient of lower-tropospheric heating is lessened during peak rainfall in the AM3 such that large positive heating extends closer to the surface. This suggests an overabundance of shallow cumuli and congesti when rainfall is most intense in the modified versions of AM3. A clear vertical tilt characterized by successive shallow, deep, and stratiform heating is evident in observations (Lin et al. 2004; Fig. 10a). AM3-A and AM3-C roughly capture the signature of shallow heating leading deep and stratiform heating, but AM3-B produces excessively deep heating both before and after peak rainfall. We further discuss these heating and moisture structures and their potential ties to convective organization next.

\footnotetext{
${ }^{5}$ The results shown are qualitatively consistent with those found using a $10^{\circ} \mathrm{S}-0^{\circ}$ latitude band.
} 


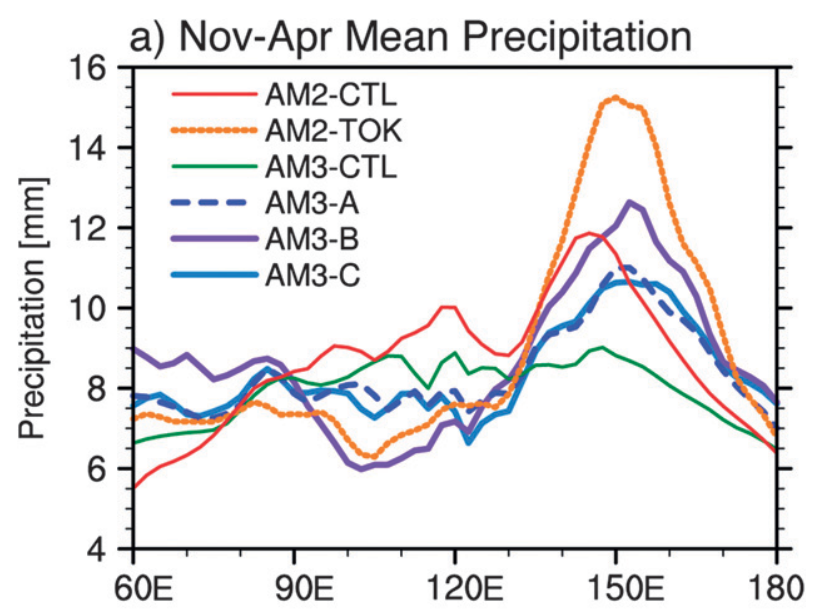

b) Nov-Apr Mean Stratiform Pct.

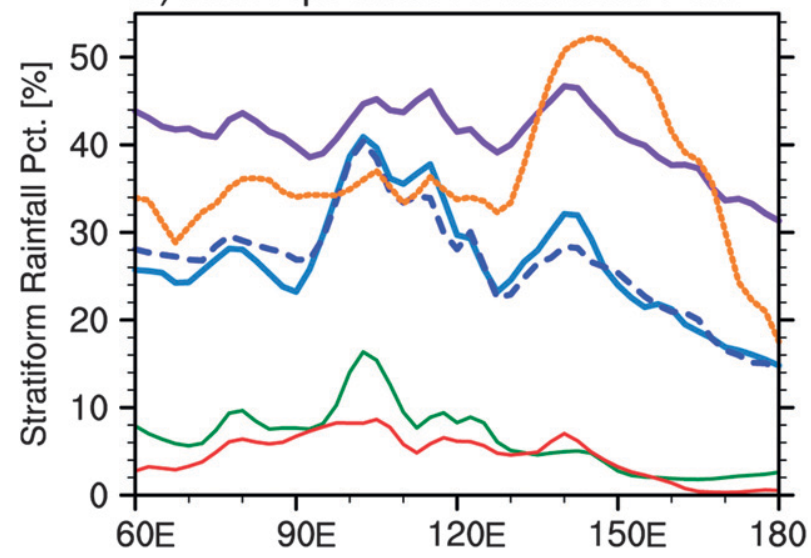

FIG. 11. Longitudinal cross sections of boreal winter mean (a) total precipitation and (b) stratiform (grid scale) precipitation as a percentage of total precipitation for all AM simulations. Latitudinal bounds are $10^{\circ} \mathrm{S}-10^{\circ} \mathrm{N}$. Stratiform rainfall fraction was computed for each day prior to space-time averaging.

\section{Discussion}

Salient features and biases of the AM simulations are summarized in Table 4. The results discussed in section 3 indicate that an improved depiction of eastwardpropagating intraseasonal disturbances is achieved when mechanisms that suppress deep convection are implemented in the AM3. This GCM behavior is not unique to the GFDL AM and is documented extensively in the modeling literature (e.g., Tokioka et al. 1988; Hannah and Maloney 2011; Kim et al. 2011). The improvements made to convectively coupled Kelvin waves and the MJO come at the cost of a degraded mean state that includes a drying and cooling of the tropical troposphere and a possible overestimation of equatorial total precipitation. Additionally, phase speeds of the AM3simulated eastward-propagating convective systems are faster than the observed MJO phase speed, particularly for disturbances in the west Pacific region (see Table 4). Despite these deficiencies, the AM3 simulations provide new and useful information that may contribute to a better understanding of the physical processes associated with intraseasonal convective systems. Our preliminary examination of the modified AM3 suggests a link between the degree of organization of intraseasonal disturbances and their corresponding heating and moisture structures (Figs. 9 and 10). In this section, we investigate in greater detail how differences in these structures might impact the intraseasonal convective signals seen in the AM3.

Some GCM studies show that MJO simulation can be improved if the fraction of stratiform (grid scale) to total precipitation is increased (Fu and Wang 2009; Seo and Wang 2010). In these studies, MJO-like disturbances become much weaker when turbulent entrainment and detrainment along the edges of either deep or shallow convective plumes are set to zero [i.e., $E_{u}^{(1)}=D_{u}^{(1)}=0$ in Eq. (12) of Tiedtke (1989)]. The authors assert that detrainment from convective clouds moistens the gridscale environment and promotes grid-scale precipitation. The results of $\mathrm{Fu}$ and Wang emphasize the direct interaction between grid-scale precipitation heating and lowfrequency disturbances, and their explanation of more vigorous $\mathrm{MJO}$ events invokes stratiform instability arguments (Mapes 2000; Kuang 2008). To investigate the applicability of this hypothesis to the AM3, we present longitudinal cross sections of boreal winter mean total precipitation (Fig. 11a) and large-scale ${ }^{6}$ precipitation as a percentage of total precipitation (Fig. 11b). In both AM2 and AM3, modifications that suppress deep convection and increase the percentage of time-mean gridscale precipitation (Fig. 11b) are associated with enhanced intraseasonal variability (cf. Fig. 6). Returning to Fig. 4, AM3-B is drier than AM3-A and AM3-C above $700 \mathrm{hPa}$ but has equal or slightly higher humidity below $700 \mathrm{hPa}$. This is qualitatively consistent with Fig. $8 \mathrm{a}$ of $\mathrm{Fu}$ and Wang (2009) and suggests that, in a comparison of AM3 simulations with identical convective closure and trigger assumptions, a drier midtroposphere is associated with weaker intraseasonal disturbances. Importantly, however, simply increasing the percentage of time-mean grid-scale precipitation does not necessarily improve intraseasonal convective organization in the AM3. Figure 8 indicates that AM3-A and AM3-C have more robust and coherent signals of intraseasonal convective disturbances

\footnotetext{
6 "Large-scale" precipitation reported in AM3 is from grid-scale stratiform clouds only and does not include contributions from mesoscale anvils, so a direct comparison to observed percentages of stratiform to total precipitation (e.g., Schumacher and Houze 2003) is not recommended.
} 
(a) AM3-CTL

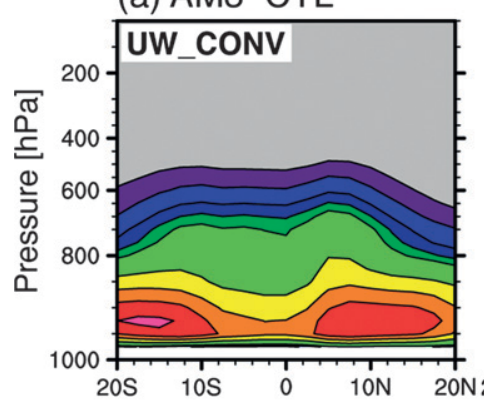

(b) $\mathrm{AM} 3-\mathrm{A}$

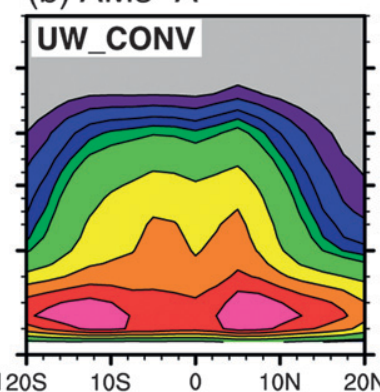

(c) AM3-B

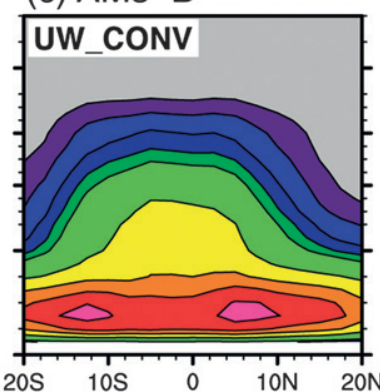

(d) AM3-C

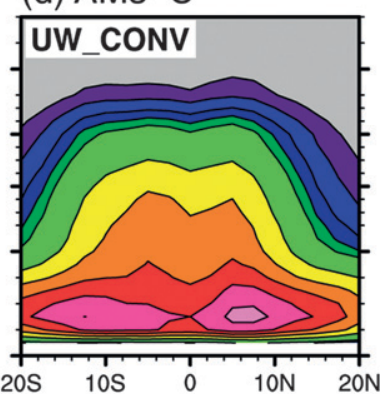

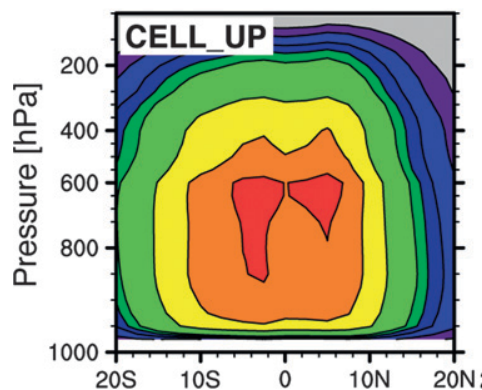
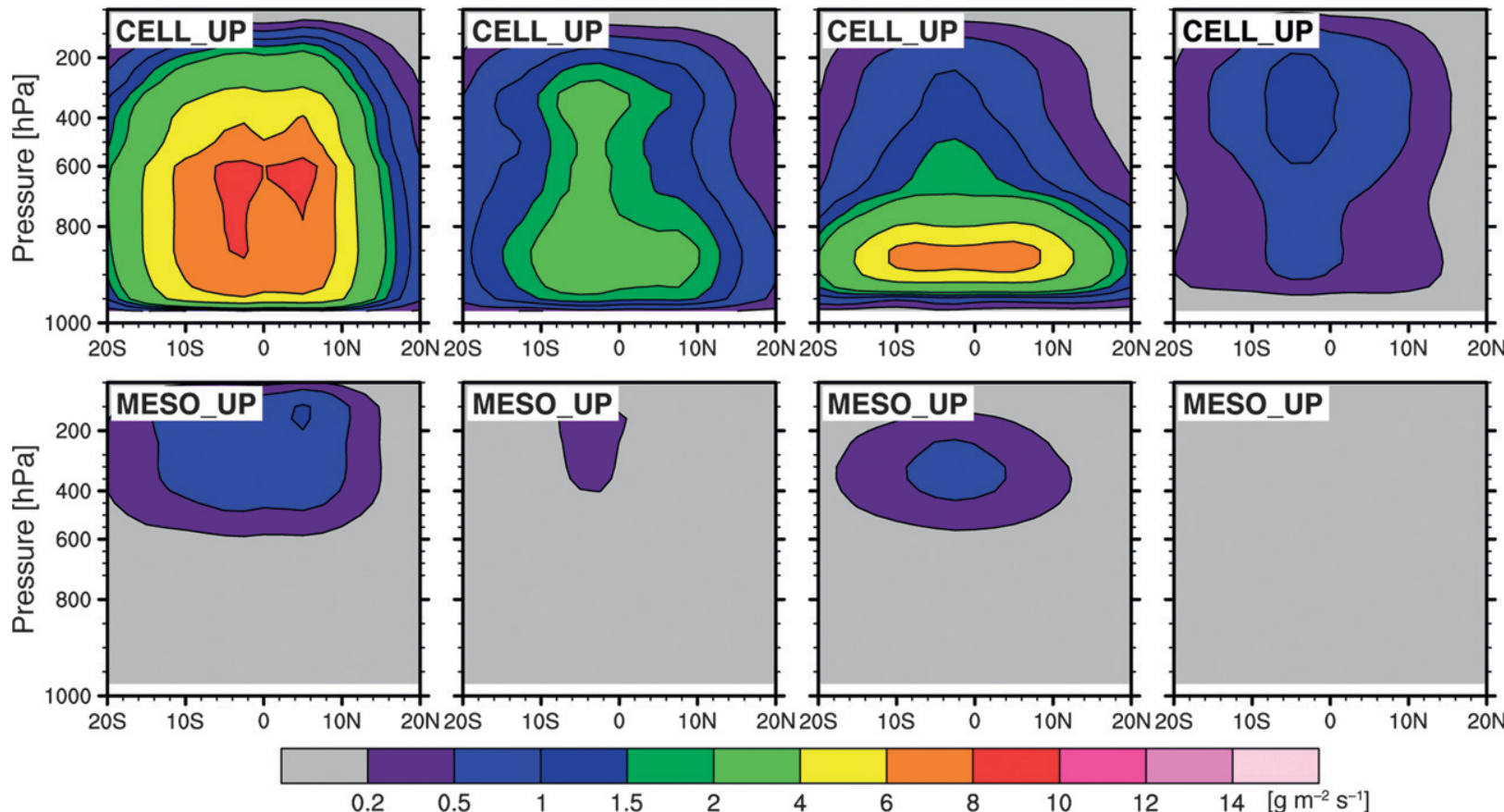

MESO UP

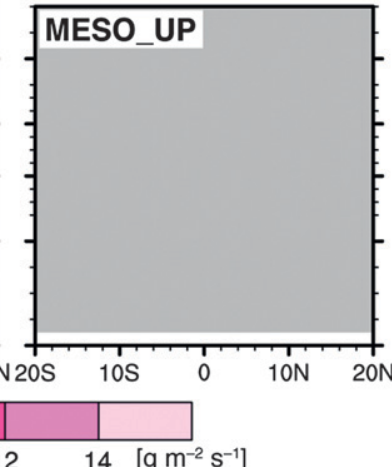

FIG. 12. Boreal winter mean (November-April) parameterized mass fluxes from the (top) shallow convection scheme UW_CONV, (middle) deep convection scheme (upward only, CELL_UP), and (bottom) mesoscale cloud scheme (upward only, MESO_UP) for all AM3 simulations.

in comparison with AM3-B despite the fact that percentages of grid-scale precipitation, at least in the time mean, are larger in AM3-B (Fig. 11b). We also examined the behavior of grid-scale precipitation fraction in an intraseasonal context. To do this, we produced plots of anomalous daily grid-scale rainfall fraction regressed onto an MJO total precipitation index at various longitudes between $60^{\circ} \mathrm{E}$ and $180^{\circ}$. These results (not shown) agree with those depicted in Fig. 11b and indicate a greater gridscale rainfall fraction in AM3-B compared to AM3-A or AM3-C. Additional work is needed to clarify the interactions among humidity, grid-scale precipitation, and the depiction of intraseasonal disturbances in the AM3.

We further investigate the link between convection and large-scale circulations by examining Indo-Pacific boreal winter mean convective mass fluxes that are output directly from the AM3 convective parameterizations (i.e., are not computed using grid-scale vertical velocities; Fig. 12). Our modifications to the convective closure and trigger assumptions strongly reduce upward mass fluxes by deep convective cells (second row of Fig. 12). Upward mass fluxes within mesoscale anvils are also reduced in step with the weakened deep cumuli because these cumuli act as a main source of water substance for the anvil clouds. In response to the suppressed deep convection, activity from the shallow convective scheme increases in the lower troposphere and expands upward (top row of Fig. 12). Shallow convection is particularly enhanced in AM3-A and AM3-C relative to AM3-B. We note that the shallow convection scheme is that of a highly entraining plume, where the cloud top is a function of plume buoyancy. As such, modifications applied to the AM3 that limit the ability of deep convection to reduce instability ultimately result in stronger and deeper plumes 

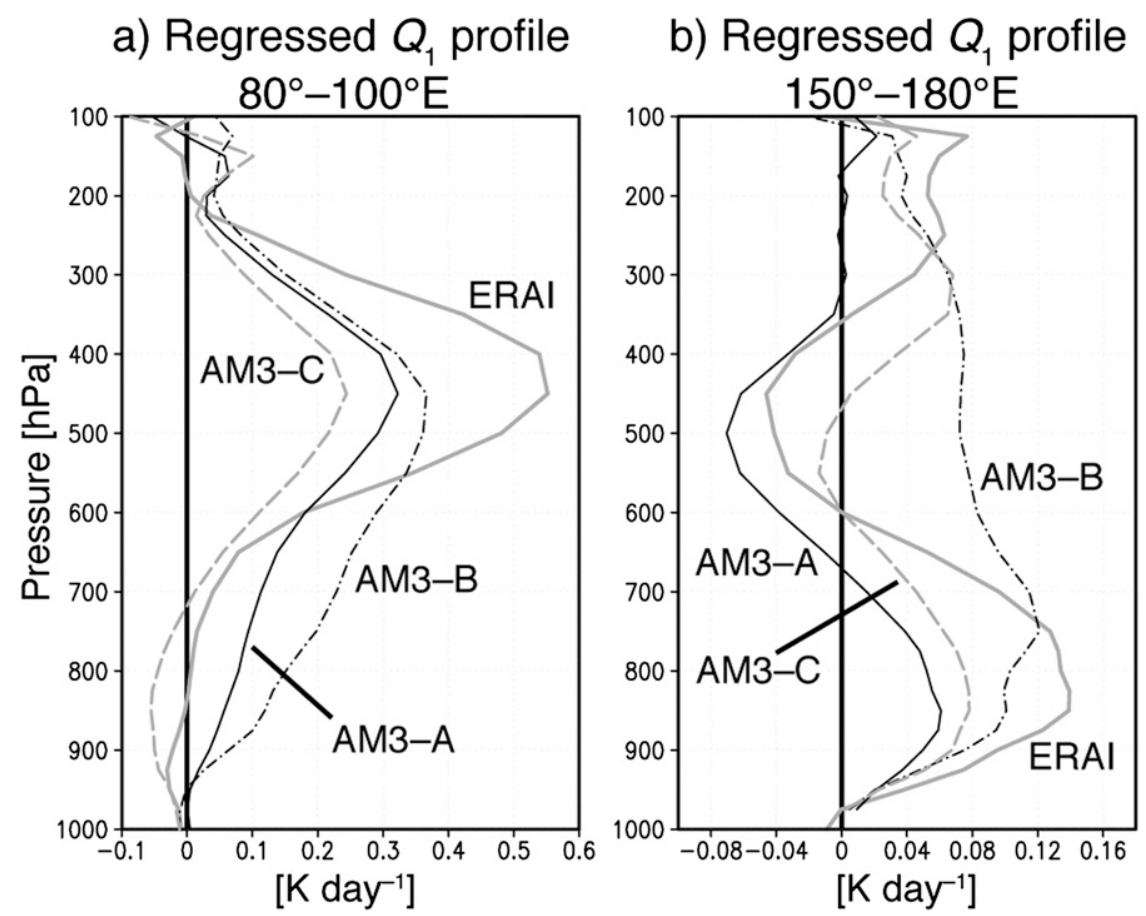

FIG. 13. Vertical profiles of regressed apparent convective heating $Q_{1}$ taken from Fig. 10 and averaged between (a) $80^{\circ}$ and $100^{\circ} \mathrm{E}$, (b) $150^{\circ} \mathrm{E}$ and $180^{\circ}$.

produced by the shallow convection parameterization. The interplay between stratiform (grid scale) and shallow convective activity in the AM3 is evident in a comparison of boreal winter mean rainfall associated with largescale and shallow convective processes (not shown). In the AM3 simulations with robust intraseasonal variability (AM3-A and AM3-C), time-mean shallow convection increases as grid-scale precipitation decreases. The opposite behavior occurs in the AM3 version with weaker intraseasonal variability (AM3-B).

Shallow convective activity may be stronger in a timemean sense in the AM3-A and AM3-C simulations, but are these differences in diabatic heating manifested on intraseasonal scales as well? Figure 13 depicts the vertical structure of the effective heat source, $Q_{1}$ (Yanai et al. 1973), taken from the linear regressions of Fig. 10 and averaged over selected longitude ranges to capture the dominant heating signatures to the west and east of peak rainfall at $120^{\circ} \mathrm{E}$. We omit heating profiles at the longitude of peak rainfall because they are qualitatively similar among the models, with the exception that the modified AM3 version with weaker intraseasonal disturbances (AM3-B) has a slightly weaker upper-tropospheric heating maximum (and thus a slightly less top-heavy profile) compared to AM3-A and AM3-C. In Fig. 13b, the observed heating profile over the west Pacific is bottom heavy with a peak heating near $850 \mathrm{hPa}$ and cooling in the midtroposphere, in agreement with the TRMM-based results of Lau and Wu (2010). A similar structure is noted for AM3-A and AM3-C, but AM3-B reveals a shallow heating peak closer to $725 \mathrm{hPa}$ and a lack of cooling anywhere in the troposphere. Similar differences between the AM3-B heating profiles and the TRMM results of Lau and $\mathrm{Wu}$ (2010) are seen to the west of maximum rainfall where stratiform processes are expected to dominate (Fig. 13a). Here, top-heavy heating is evident in ERAI, with a peak near $450 \mathrm{hPa}$ and a minimum in the lower troposphere. The upper-level heating is too weak in all AM3 versions, but the modified AM3 versions with more robust intraseasonal disturbances (AM3-A and AM3-C) produce a much stronger reduction in low-level heating (and thus a larger vertical heating gradient in the middle troposphere) compared to AM3-B.

The shape of the vertical heating profile can impact the large-scale flow and thus the distribution of moisture and degree of atmospheric stability. Wu (2003) argues that a bottom-heavy heating profile associated with shallow convection generates stronger near-surface circulations and enhances low-level moisture convergence to the east of deep convection, and that this shallow heating can sustain MJO-like systems against dissipation. Figure 14 depicts anomalies of $-\nabla \cdot q \mathbf{v}_{h}$ regressed onto a standardized precipitation index at $120^{\circ} \mathrm{E}$, where $q$ is 

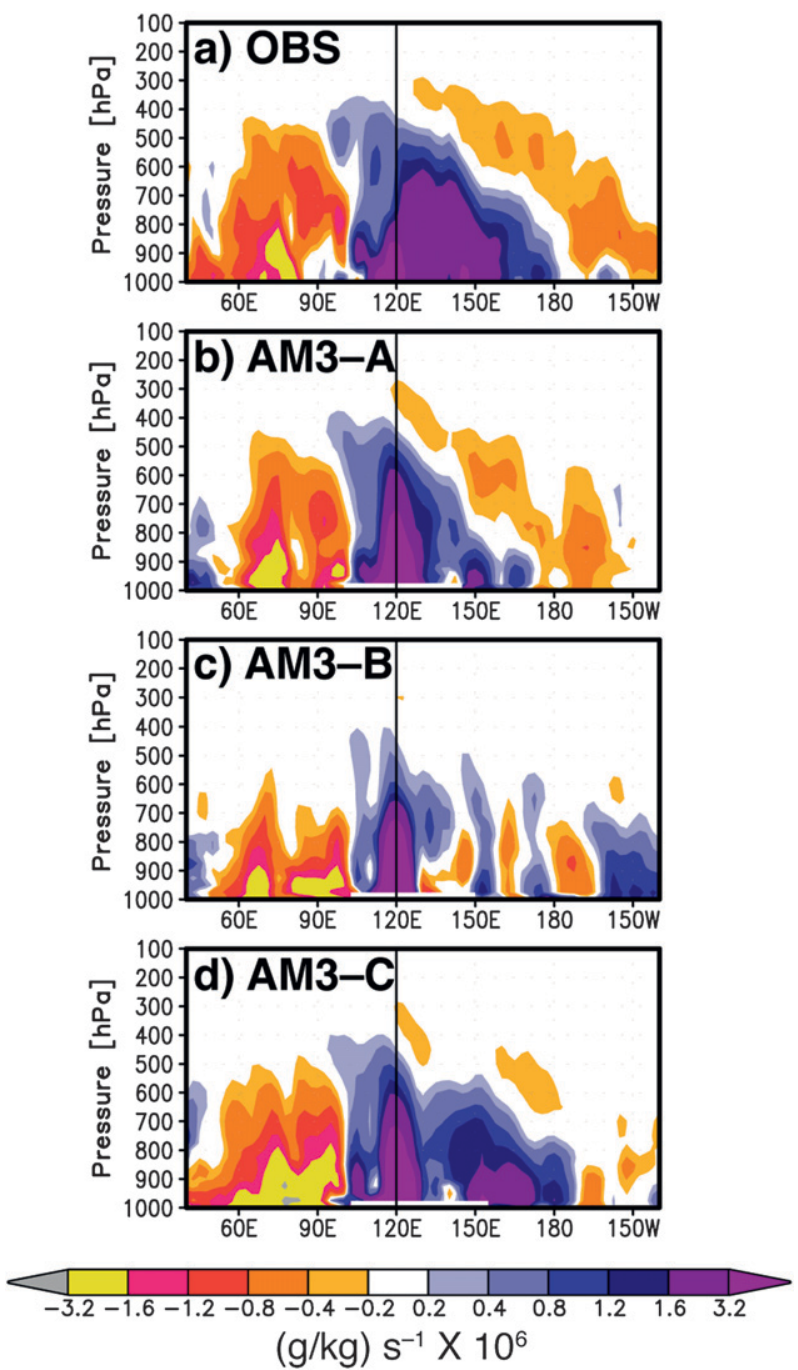

FIG. 14. As in Fig. 10 but for anomalous moisture convergence, $-\boldsymbol{\nabla} \cdot q \mathbf{v}_{h}$, linearly regressed onto $20-100$-day filtered precipitation at $120^{\circ} \mathrm{E}$. All fields are averaged between $15^{\circ} \mathrm{S}$ and $15^{\circ} \mathrm{N}$. Here $q$ is specific humidity and $\mathbf{v}_{h}$ is horizontal vector wind. We use ERAI and TRMM for the observed wind, specific humidity, and rainfall fields.

specific humidity and $\mathbf{v}_{h}$ is horizontal vector wind. Both fields are averaged between $15^{\circ} \mathrm{S}$ and $15^{\circ} \mathrm{N}$. In ERAI (Fig. 14a), positive moisture convergence anomalies develop within the boundary layer during the suppressed convective phase (i.e., in the west Pacific) and then gradually deepen toward the disturbance center. A similar pattern is seen in AM3-A and AM3-C - the two modified AM3 versions with more robust intraseasonal disturbances-but the suppressed-phase moisture convergence in AM3-B is irregular and weak. Boundary layer moistening along the leading (eastern) edge of the disturbance is mainly associated with meridional convergence (not shown). This suggests that the convergence may be primarily frictional in origin, a process whose importance to the MJO has been debated (e.g., Wang 1988; Moskowitz and Bretherton 2000).

Figures 13 and 14 indicate a clear link between the vertical heating profiles and large-scale circulations associated with intraseasonal convective disturbances in the AM3. In the two modified AM3 versions with the strongest inhibition of deep convection (AM3-A and AM3-C), time-mean shallow convective activity is enhanced relative to a third modified AM3 version with weaker deep convective suppression (AM3-B). These differences in heating profiles are associated with subseasonal variability rather than simply being features of the time means. In AM3-A and AM3-C, the peak of shallow convective heating is more prominent and the vertical gradient of heating in the lower to midtroposphere is larger ahead of the intraseasonal deep convective center (Fig. 13). This sharper heating peak effectively drives low-level circulations and moisture convergence that can promote subsequent convective development. A larger vertical gradient of upper-tropospheric heating associated with stratiform processes is also seen in AM3-A and AM3-C relative to AM3-B (Fig. 13). It is unclear exactly why the stratiform signal trailing the deep convective center is enhanced in the modified AM3 versions with stronger deep convective suppression (AM3-A and AM3-C), although it seems plausible that the overall improved strength and organization of the disturbances themselves somehow promote improved organization of the heating. Lau and $\mathrm{Wu}$ (2010) assert that horizontal variability of the vertical heating profile likely contributes to the modulation of intraseasonal deep convection and the transition of MJO phases. For example, those authors demonstrate that shallow cumulus heating preconditions the environment ahead of the MJO while stratiform heating entrains dry midtropospheric air and suppresses deep convection following the MJO. Together, the differences in the distributions of the simulated heating structures and their associated circulations are related to the degree of organization of intraseasonal convective disturbances in the AM3.

\section{Conclusions}

Intraseasonal variability in four GFDL AM3 simulations is examined and compared to previous simulations of the AM2. In contrast to AM2, AM3 employs new treatments of deep and shallow convection. In particular, cloud-aerosol interactions are introduced by computing cumulus cell-scale vertical velocities, and the parameterization of convective cloud systems now includes dynamically active mesoscale clouds that modulate the transfer of water substance between cumuli and their 
environment. The default AM3 generates a realistic mean state but lacks intraseasonal variability. Changes made to the deep convective closure and trigger assumptions inhibit the most penetrative cumuli and result in a substantial increase in the amplitude of eastwardpropagating intraseasonal disturbances. As is typical of many other GCMs (Kim et al. 2011), the improved simulation of intraseasonal variability comes at the cost of a degraded mean state that includes possible wet biases in equatorial precipitation and a weakening of low-level westerlies in the Indo-Pacific region.

The eastward-propagating intraseasonal features produced by the modified AM3 versions have unrealistically narrow longitudinal scales and propagate at speeds closer to those of convectively coupled Kelvin waves in the west Pacific (Wheeler et al. 2000). Notable differences in the degree of convective organization and signal coherence exist among the modified AM3 simulations and may be associated with intraseasonal heating structures and their impact on low-level circulation and moisture availability, particularly for those processes related to shallow convection. In the two versions of the AM3 with the strongest MJO-like signal (AM3-A and AM3-C), a more prominent peak in shallow heating occurs with enhanced lowlevel convergence that increases moisture accumulation ahead of the deep convective center. The tropospheric heating gradient and low-level convergence leading the convective center are substantially weaker in the AM3 version with more disorganized intraseasonal convection (AM3-B). Following the deep convective center, AM3-A and AM3-C depict a more pronounced stratiform heating signal relative to AM3-B. Stratiform cloud processes can modulate intraseasonal deep convection and the transition of MJO phases (Lau and Wu 2010) and may also be contributing to the differences among the modified AM3 simulations in addition to shallow heating differences.

Although we have provided new insight into the mechanisms that contribute to intraseasonal convective organization within the GFDL AM3, many issues have yet to be addressed. One such issue is the inability of the AM3 to produce a realistic mean state concurrent with a reasonable degree of intraseasonal variability. Another involves the dilemma by which intraseasonal convection is improved. On one hand, we have found that suppressing deep convection enhances intraseasonal variability; however, deep convection suppression also limits the source of water substance for the mesoscale clouds that are clearly important in simulated and observed MJOs (Fu and Wang 2009; Lau and Wu 2010). Additionally, our use of prescribed SSTs in the AM simulations precludes realistic air-sea interactions that strongly modulate intraseasonal convection in GCMs (Waliser et al.
1999) and in nature (Roundy and Kiladis 2006). Further research is warranted to explore these and other issues related to simulated intraseasonal convection in the AM3.

Acknowledgments. We thank J.-L. Lin and three anonymous reviewers for their helpful comments on this manuscript. This work was supported by award NA08OAR4320893 (JJB, EDM) and NA08OAR4320912 (AHS) from the National Oceanic and Atmospheric Administration, U.S. Department of Commerce, and by the Climate and Large-Scale Dynamics Program of the National Science Foundation under Grants AGS-1025584 (EDM) and ATM-1062161 (EDM). The statements, findings, conclusions, and recommendations do not necessarily reflect the views of NSF, NOAA, or the Department of Commerce.

\section{REFERENCES}

Adler, R. F., and Coauthors, 2003: The version-2 Global Precipitation Climatology Project (GPCP) monthly precipitation analysis (1979-present). J. Hydrometeor., 4, 1147-1167.

Anderson, J. L., and Coauthors, 2004: The new GFDL global atmosphere and land model AM2-LM2: Evaluation with prescribed SST simulations. J. Climate, 17, 4641-4673.

Arakawa, A., and W. H. Schubert, 1974: Interaction of a cumulus cloud ensemble with the large-scale environment, Part I. J. Atmos. Sci., 31, 674-701.

Benedict, J. J., and D. A. Randall, 2007: Observed characteristics of the MJO relative to maximum rainfall. J. Atmos. Sci., 64, 2332-2354.

Berrisford, P., D. Dee, K. Fielding, M. Fuentes, P. Kallberg, S. Kobayashi, and S. Uppala, 2009: The ERA-Interim archive. ECMWF Tech. Rep. 1, 16 pp. [Available online at http://www. ecmwf.int/publications/library/do/references/show?id=89203.]

Bretherton, C. S., J. R. McCaa, and H. Grenier, 2004: A new parameterization for shallow cumulus convection and its application to marine subtropical cloud-topped boundary layers. Part I: Description and 1D results. Mon. Wea. Rev., 132, 864882.

Donner, L. J., 1993: A cumulus parameterization including mass fluxes, vertical momentum dynamics, and mesoscale effects. J. Atmos. Sci., 50, 889-906.

— , and V. T. Phillips, 2003: Boundary layer control on convective available potential energy: Implications for cumulus parameterization. J. Geophys. Res., 108, 4701, doi:10.1029/ 2003JD003773.

— C. J. Seman, R. S. Hemler, and S. Fan, 2001: A cumulus parameterization including mass fluxes, convective vertical velocities, and mesoscale effects: Thermodynamic and hydrological aspects in a general circulation model. J. Climate, 14, 3444-3463.

— , and Coauthors, 2011: The dynamical core, physical parameterizations, and basic simulation characteristics of the atmospheric component AM3 of the GFDL global coupled model CM3. J. Climate, 24, 3484-3519.

Emanuel, K. A., 1987: An air-sea interaction model of intraseasonal oscillations in the tropics. J. Atmos. Sci., 44, 23242340 
1993: The effect of convective response time on WISHE modes. J. Atmos. Sci., 50, 1763-1776.

Frierson, D. M. W., 2007: Convectively coupled Kelvin waves in an idealized moist general circulation model. J. Atmos. Sci., 64, 2076-2090.

— D. Kim, I.-S. Kang, M.-I. Lee, and J. Lin, 2011: Structure of AGCM-simulated convectively coupled Kelvin waves and sensitivity to convective parameterization. J. Atmos. Sci., 68, $26-45$.

$\mathrm{Fu}, \mathrm{X}$., and B. Wang, 2009: Critical roles of the stratiform rainfall in sustaining the Madden-Julian oscillation: GCM experiments. J. Climate, 22, 3939-3959.

Hannah, W. M., and E. D. Maloney, 2011: The role of moistureconvection feedbacks in simulating the Madden-Julian oscillation. J. Climate, 24, 2754-2770.

Hayashi, Y., 1970: A theory of large-scale equatorial waves generated by condensation heat and accelerating the zonal wind. J. Meteor. Soc. Japan, 48, 140-160.

Hendon, H. H., and M. L. Salby, 1994: The life cycle of the Madden-Julian oscillation. J. Atmos. Sci., 51, 2225-2237.

Holloway, C. E., and J. D. Neelin, 2009: Moisture vertical structure, column water vapor, and tropical deep convection. J. Atmos. Sci., 66, 1665-1683.

Houze, R. A., Jr., 1982: Cloud clusters and large-scale vertical motion in the tropics. J. Meteor. Soc. Japan, 60, 396-410.

_- 1989: Observed structure of mesoscale convective systems and implications for large-scale heating. Quart. J. Roy. Meteor. Soc., 115, 425-461.

Huffman, G. J., and Coauthors, 2007: The TRMM Multisatellite Precipitation Analysis (TMPA): Quasi-global, multiyear, combined-sensor precipitation estimates at fine scales. J. Hydrol., 8, $38-55$.

Hurrell, J. W., J. J. Hack, D. Shea, J. M. Caron, and J. Rosinski, 2008: A new sea surface temperature and sea ice boundary dataset for the Community Atmosphere Model. J. Climate, 21, 5145-5153

Inness, P. M., J. M. Slingo, E. Guilyardi, and J. Cole, 2003: Simulation of the Madden-Julian oscillation in a coupled general circulation model. Part II: The role of the basic state. J. Climate, 16, 365-382.

Jia, X., C. Li, N. Zhou, and J. Ling, 2010: The MJO in an AGCM with three different cumulus parameterization schemes. Dyn. Atmos. Oceans, 49, 141-163.

Kato, S., and Coauthors, 2011: Improvements of top-of-atmosphere and surface irradiance computations with CALIPSO-, CloudSat-, and MODIS-derived cloud and aerosol properties. J. Geophys. Res., 116, D19209, doi:10.1029/2011JD016050.

Kemball-Cook, S. R., and B. C. Weare, 2001: The onset of convection in the Madden-Julian oscillation. J. Climate, 14, 780-793.

Khouider, B., and A. J. Majda, 2007: A simple multicloud parameterization for convectively coupled tropical waves. Part II: Nonlinear simulations. J. Atmos. Sci., 64, 381-400.

— A. At-Cyr, A. J. Majda, and J. Tribbia, 2011: The MJO and convectively coupled waves in a coarse-resolution GCM with a simple multicloud parameterization. J. Atmos. Sci., 68, 240-264.

Kiladis, G. N., K. H. Straub, and P. T. Haertel, 2005: Zonal and vertical structure of the Madden-Julian oscillation. J. Atmos. Sci., 62, 2790-2809.

- M. C. Wheeler, P. T. Haertel, K. H. Straub, and P. E. Roundy, 2009: Convectively coupled equatorial waves. Rev. Geophys., 47, RG2003, doi:10.1029/2008RG000266.

Kim, D., and Coauthors, 2009: Application of MJO simulation diagnostics to climate models. J. Climate, 22, 6413-6436.
, A. H. Sobel, E. D. Maloney, D. M. W. Frierson, and I.-S. Kang, 2011: A systematic relationship between intraseasonal variability and mean state bias in AGCM simulations. J. Climate, 24, 5506-5520.

Kuang, Z., 2008: A moisture-stratiform instability for convectively coupled waves. J. Atmos. Sci., 65, 834-854.

Kummerow, C., and Coauthors, 2000: The status of the Tropical Rainfall Measuring Mission (TRMM) after two years in orbit. J. Appl. Meteor., 39, 1965-1982.

Lappen, C.-L., and C. Schumacher, 2012: Heating in the tropical atmosphere: What level of detail is critical for acurate MJO simulations in GCMs? Climate Dyn., 39, 2547-2568.

Lau, K.-M., and H.-T. Wu, 2010: Characteristics of precipitation, cloud, and latent heating associated with the Madden-Julian oscillation. J. Climate, 23, 504-518.

Leary, C. A., and R. A. Houze, 1980: The contribution of mesoscale motions to the mass and heat fluxes of an intense tropical convective system. J. Atmos. Sci., 37, 784-796.

Li, C., X. Jia, J. Ling, W. Zhou, and C. Zhang, 2009: Sensitivity of MJO simulations to diabatic heating profiles. Climate Dyn., 32, 167-187.

Liebmann, B., and C. A. Smith, 1996: Description of a complete (interpolated) outgoing longwave radiation dataset. Bull. Amer. Meteor. Soc., 77, 1275-1277.

Lin, J., B. Mapes, M. Zhang, and M. Newman, 2004: Stratiform precipitation, vertical heating profiles, and the Madden-Julian oscillation. J. Atmos. Sci., 61, 296-309.

_ - and Coauthors, 2006: Tropical intraseasonal variability in 14 IPCC AR4 climate models. Part I: Convective signals. J. Climate, 19, 2665-2690.

_ M.-I. Lee, D. Kim, I.-S. Kang, and D. M. W. Frierson, 2008: The impacts of convective parameterization and moisture triggering on AGCM-simulated convectively coupled equatorial waves. J. Climate, 21, 883-909.

Lin, X., and R. H. Johnson, 1996: Heating, moistening, and rainfall over the western Pacific warm pool during TOGA COARE. J. Atmos. Sci., 53, 3367-3383.

Madden, R. A., and P. R. Julian, 1971: Detection of a 40-50 day oscillation in the zonal wind in the tropical Pacific. J. Atmos. Sci., 28, 702-708.

Maloney, E. D., and D. L. Hartmann, 2001: The sensitivity of intraseasonal variability in the NCAR CCM3 to changes in convective parameterization. J. Climate, 14, 2015-2034.

Mapes, B. E., 2000: Convective inhibition, subgrid-scale triggering energy, and stratiform instability in a toy tropical wave model. J. Atmos. Sci., 57, 1515-1535.

Moncrieff, M. W., 1992: Organized convective systems: Archetypal dynamical models, mass and momentum flux theory, and parametrization. Quart. J. Roy. Meteor. Soc., 118, 819-850.

_ 2004: Analytic representation of the large-scale organization of tropical convection. J. Atmos. Sci., 61, 1521-1538.

Moorthi, S., and M. J. Suarez, 1992: Relaxed Arakawa-Schubert: A parameterization of moist convection for general circulation models. Mon. Wea. Rev., 120, 978-1002.

Moskowitz, B. M., and C. S. Bretherton, 2000: An analysis of frictional feedback on a moist equatorial Kelvin mode. J. Atmos. Sci., 57, 2188-2206.

Neale, R. B., J. H. Richter, and M. Jochum, 2008: The impact of convection on ENSO: From a delayed oscillator to a series of events. J. Climate, 21, 5904-5924.

Neelin, J. D., I. M. Held, and K. H. Cook, 1987: Evaporation-wind feedback and low-frequency variability in the tropical atmosphere. J. Atmos. Sci., 44, 2341-2348. 
Reynolds, R. W., N. A. Rayner, T. M. Smith, D. C. Stokes, and W. Wang, 2002: An improved in situ and satellite SST analysis for climate. J. Climate, 15, 1609-1625.

Romps, D. M., 2010: A direct measure of entrainment. J. Atmos. Sci., 67, 1908-1927.

Roundy, P. E., 2012a: Observed structure of convectively coupled waves as a function of equivalent depth: Kelvin waves and the Madden-Julian oscillation. J. Atmos. Sci., 69, 2097-2106.

__ 2012b: The spectrum of convectively coupled Kelvin waves and the Madden-Julian oscillation in regions of low-level easterly and westerly background flow. J. Atmos. Sci., 69, 2107-2111.

—, and G. N. Kiladis, 2006: Observed relationships between oceanic Kelvin waves and atmospheric forcing. J. Climate, 19, 5253-5272.

Salzmann, M., Y. Ming, J.-C. Golaz, P. A. Ginoux, H. Morrison, A. Gettelman, M. Krämer, and L. J. Donner, 2010: Two-moment bulk stratiform cloud microphysics in the GFDL AM3 GCM: Description, evaluation, and sensitivity tests. Atmos. Chem. Phys., 10, 8037-8064.

Schumacher, C., and R. A. Houze, 2003: The TRMM precipitation radar's view of shallow, isolated rain. J. Appl. Meteor., 42, 1519-1524.

Seo, K.-H., and W. Wang, 2010: The Madden-Julian oscillation simulated in the NCEP Climate Forecast System model: The importance of stratiform heating. J. Climate, 23, 4770-4793.

Slingo, J. M., and Coauthors, 1996: Intraseasonal oscillations in 15 atmospheric general circulation models: Results from an AMIP diagnostic subproject. Climate Dyn., 12, 325-357.

Sobel, A. H., E. D. Maloney, G. Bellon, and D. M. Frierson, 2010: Surface fluxes and tropical intraseasonal variability: A reassessment. J. Adv. Model. Earth Syst., 2 (2), doi:10.3894/ JAMES.2010.2.2.

Sperber, K., S. Gualdi, S. Legutke, and V. Gayler, 2005: The Madden-Julian oscillation in ECHAM4 coupled and uncoupled general circulation models. Climate Dyn., 25, 117140.

Straub, K. H., P. T. Haertel, and G. N. Kiladis, 2010: An analysis of convectively coupled Kelvin waves in 20 WCRP CMIP3 global coupled climate models. J. Climate, 23, 3031-3056.

Subramanian, A. C., M. Jochum, A. J. Miller, R. Murtugudde, R. B. Neale, and D. E. Waliser, 2011: The Madden-Julian oscillation in CCSM4. J. Climate, 24, 6261-6282.

Tiedtke, M., 1989: A comprehensive mass flux scheme for cumulus parameterization in large-scale models. Mon. Wea. Rev., 117, 1779-1800.

Tokioka, T., K. Yamazaki, A. Kitoh, and T. Ose, 1988: The equatorial 30-60 day oscillation and the Arakawa-Schubert penetrative cumulus parameterization. J. Meteor. Soc. Japan, 66, 883-901.

Trenberth, K. E., J. T. Fasullo, and J. Kiehl, 2009: Earth's global energy budget. Bull. Amer. Meteor. Soc., 90, 311-323.

Waliser, D. E., K. M. Lau, and J. H. Kim, 1999: The influence of coupled sea surface temperatures on the Madden-Julian oscillation: A model perturbation experiment. J. Atmos. Sci., 56, 333-358.

Wang, B., 1988: Dynamics of tropical low-frequency waves: An analysis of the moist Kelvin wave. J. Atmos. Sci., 45, 20512065.

Wheeler, M., and G. N. Kiladis, 1999: Convectively coupled equatorial waves: Analysis of clouds and temperature in the wavenumber-frequency domain. J. Atmos. Sci., 56, 374-399.

$\longrightarrow,-$, and P. J. Webster, 2000: Large-scale dynamical fields associated with convectively coupled equatorial waves. J. Atmos. Sci., 57, 613-640.

Wilcox, E. M., and L. J. Donner, 2007: The frequency of extreme rain events in satellite rain-rate estimates and an atmospheric general circulation model. J. Climate, 20, 53-69.

Wu, Z., 2003: A shallow CISK, deep equilibrium mechanism for the interaction between large-scale convection and large-scale circulations in the tropics. J. Atmos. Sci., 60, 377-392.

Yanai, M., S. Esbensen, and J.-H. Chu, 1973: Determination of bulk properties of tropical cloud clusters from large-scale heat and moisture budgets. J. Atmos. Sci., 30, 611-627.

Yuan, J., and R. A. Houze, 2010: Global variability of mesoscale convective system anvil structure from A-Train satellite data. J. Climate, 23, 5864-5888.

Zhang, C., and Coauthors, 2006: Simulations of the Madden-Julian oscillation in four pairs of coupled and uncoupled global models. Climate Dyn., 27, 573-592.

Zhang, G. J., 2002: Convective quasi-equilibrium in midlatitude continental environment and its effect on convective parameterization. J. Geophys. Res., 107, 4220, doi:10.1029/ 2001JD001005.

_ and M. Mu, 2005: Simulation of the Madden-Julian oscillation in the NCAR CCM3 using a revised Zhang-McFarlane convection parameterization scheme. J. Climate, 18, 40464064.

Zhao, M., I. M. Held, S. J. Lin, and G. A. Vecchi, 2009: Simulations of global hurricane climatology, interannual variability, and response to global warming using a $50-\mathrm{km}$ resolution GCM. J. Climate, 22, 6653-6678.

Zhou, L., R. Neale, M. Jochum, and R. Murtugudde, 2012: Improved Madden-Julian oscillations with improved physics: The impact of modified convection parameterizations. J. Climate, 25, 1116-1136. 